\title{
Quantificação da Deformação Finita nos Metagranitoides Cariris Velhos na Região de Alagoa Grande (PB)
}

\author{
Finite Strain Quantification in Cariris Velhos Metagranitoids of Alagoa Grande (PB) \\ Sérgio Wilians de Oliveira Rodrigues' (srodrigues@sp.cprm.gov.br), Carlos José Archanjo² (archan@usp.br), \\ Carlos Henrique Grohmann³ (guano@usp.br) \\ 'Serviço Geológico do Brasil - Superintendência Regional de São Paulo \\ R. Costa 55, CEP 01304-010, São Paulo, SP, BR \\ ${ }^{2}$ Departamento de Mineralogia e Geotectônica - Instituto de Geociências - USP, São Paulo, SP, BR \\ ${ }^{3}$ Departamento de Geologia Sedimentar e Ambiental - Instituto de Geociências - USP, São Paulo, SP, BR
}

Recebido em 09 de dezembro de 2009; aceito em 14 de junho de 2010

\section{RESUMO}

Os Metagranitoides Cariris Velhos são considerados como uma das principais associações litológicas da Zona Transversal (Província Borborema - NE do Brasil). A utilização de imagens brutas e tratadas digitalmente de afloramentos dos Metagranitoides Cariris Velhos na obtenção do elipsoide de deformação foi avaliada com o emprego dos métodos do tensor de inércia e interceptos. Os resultados obtidos nas diferentes técnicas utilizadas apresentam elipsoides com geometria e parâmetros de forma semelhantes entre si, mas com grau de anisotropias diferentes. As orientações dos eixos dos elipsoides obtidos são condizentes com as estruturas geológicas observadas em campo, como a foliação principal e a lineação mineral. Entre as características observadas nos elipsoides de deformação obtidos nesse trabalho, destacam-se a forte orientação do eixo C (associado ao polo da foliação) e o predomínio de elipsoides associados a tramas planares e plano-lineares (predomínio de achatamento na deformação). A deformação observada nos Metagranitoides Cariris Velhos é associada ao desenvolvimento das zonas de cisalhamento brasilianas regionais desenvolvidas sob esforços transpressivos.

Palavras-chave: Análise da deformação; Elipsoide de deformação; Tensor de inércia; Método dos interceptos; Metagranitoides Cariris Velhos.

\begin{abstract}
The Cariris Velhos Metagranitoids are considered an important geological unit of the Transversal Zone (Borborema Province - NE Brazil). We evaluated the use of raw and processed digital images to obtain the deformation ellipsoid for the Cariris Velhos Metagranitoids using the Inertia Tensor and Intercepts methods. The ellipsoid symmetry of the deformed fabric was very similar for both methods, the Inertia Tensor and Intercepts, although with different anisotropy values. The orientations of the ellipsoid axes are similar to the orientation of geological structures observed in the field (principal foliations and mineral lineations). When analyzing the characteristics of the deformation ellipsoids obtained in this study, it is worth pointing out the strong orientation of the $\mathrm{C}$-axis (foliation pole) and the predominance of ellipsoids associated with planar to planar- linear fabrics (flattening field). The deformation observed in the Cariris Velhos Metagranitoids is associated with the development under transpressive stress of regional Brasiliano shear zones.
\end{abstract}

Keywords: Strain analysis; Deformation ellipsoid; Inertia tensor; Intercepts method; Cariris Velhos Metagranitoids. 


\section{INTRODUÇÃO}

Os Metagranitoides Cariris Velhos são considerados como uma das principais associações litológicas da Zona Transversal, que corresponde a uma megaestrutura da Província Borborema situada entre os Lineamentos Patos e Pernambuco. No geral, o termo "Metagranitoides Cariris Velhos" é associado com uma série de rochas graníticas deformadas que apresentam idades $\mathrm{U} / \mathrm{Pb}$ tonianas em zircões magmáticos ( $\sim 950 \mathrm{Ma}$ - Santos, 1995; Brito Neves et al., 2001a; Kozuch, 2003). Estas rochas são diretamente associadas com o "Evento Cariris Velhos" (Brito Neves et al., 1995) que representa um importante período de magmatismo na Província Borborema, porém com significado ainda controverso.

Nas duas últimas décadas os Metagranitoides Cariris Velhos foram alvos de estudos baseados principalmente em diferentes métodos geocronológicos $(\mathrm{U} / \mathrm{Pb}, \mathrm{Sm}-\mathrm{Nd}, \mathrm{Rb} / \mathrm{Sr}$ etc.). No entanto, apresentam uma carência de estudos mais profundos e sistemáticos de suas relações estruturais, em especial quanto à caracterização e quantificação da deformação.

Um dos objetivos deste trabalho é a obtenção da orientação preferencial de forma (OPF) em tramas minerais associadas aos Metagranitoides Cariris Velhos, de modo a obter parâmetros qualitativos e quantitativos que caracterizem a deformação imposta nestas rochas.

Os métodos de caracterização da orientação preferencial de forma (OPF) tomaram um novo impulso com a possibilidade de utilização de microcomputadores, câmeras digitais e programas específicos que conseguem tratar um grande número de informações. Estas novas tecnologias tornaram a caracterização da OPF em uma operação prática e relativamente rápida.

Neste trabalho foram utilizadas imagens de afloramento de rochas graníticas deformadas (Metagranitoides Cariris Velhos) na obtenção da OPF. Estas imagens foram trabalhadas com diferentes tratamentos digitais (análise de imagens) e métodos de cálculo de forma e orientação de elipses em análises bidimensionais (2D). Os diferentes resultados obtidos são comparados utilizando-se os parâmetros escalares (magnitude, forma) e direcionais (orientação preferencial) do elipsoide de trama (3D).

As imagens utilizadas foram obtidas em afloramentos ao longo de um perfil geológico no Rio Mamanguape, nas imediações do Município de Alagoa Grande (PB), onde ocorrem excelentes exposições dos Metagranitoides Cariris Velhos que permitem a aplicação da obtenção da OPF a partir de imagens de afloramento.

\section{CONTEXTO GEOLÓGICO REGIONAL}

A Província Borborema (Figura 1A) é uma ampla região brasiliana que compreende a região nordeste da Plata- forma Sul-americana, formada por um sistema ramificado de orógenos neoproterozoicos separados por terrenos proterozoicos que, eventualmente, apresentam núcleos arqueanos (Brito Neves, Santos, Van Schmus, 2000; Almeida et al., 1981). A Província Borborema se estende por grande parte do Nordeste brasileiro, desde os estados de Sergipe até a parte oriental do Piauí. Apresenta uma complexidade estratigráfica e geocronológica que define uma série de compartimentos tectônicos caracterizados por diferentes aspectos geológicos e geofísicos. Modelos de compartimentação tectônica foram propostos por diversos autores (por exemplo, Brito Neves, 1975, 1983; Santos e Brito Neves, 1984; Sá, 1994). Estudos baseados em diferentes métodos geocronológicos (principalmente U-Pb e Sm-Nd), têm sido utilizados por diversos autores (por exemplo, Van Schmus et al., 1995; Santos et al., 1999; Brito Neves, Santos, Van Schmus, 2000; Brito Neves et al., 2001a, 2001b; Santos, Ferreira, Silva Júnior, 2002; Brito Neves et al., 2005) na caracterização e refinamento dos compartimentos tectônicos que compõem a Província Borborema.

$\mathrm{Na}$ região de estudo afloram dois compartimentos tectônicos do arcabouço da Província Borborema (Figura 1B), a saber, de norte para sul; Terreno Alto Pajeú (TAP), composto de ortognaisses (Metagranitoides Cariris Velhos) e supracrustais (Complexo São Caetano) de idades tonianas (Brito Neves et al., 2001a; Kozuch, 2003; Santos et al., 2009); Terreno Alto Moxotó (TAM), estruturado por ortognaisses variados, migmatitos e rochas máficas-ultramáficas de idades paleoproterozoicas (Brito Neves et al., 2001b; Santos, Nutman, Brito Neves, 2004). Ambos são parte integrante do Domínio da Zona Transversal da Província Borborema, que situa-se entre os Lineamentos Patos e Pernambuco.

O denominado "Terreno Alto Moxotó" (Brito Neves et al., 2001b; Santos, Ferreira, Silva Júnior, 2002), apresenta quatro tipos litológicos principais, a saber: ortognaisses bandados laminados, ortognaisses graníticos e granodioríticos, rochas máficas-ultramáficas metamorfizadas (principalmente anfibolitos) e gnaisses aluminosos caracterizados por Santos, Ferreira e Silva Júnior (2002) como Complexo Sertânia. As determinações geocronológicas dos ortognaisses bandados apresentam idades $\mathrm{U} / \mathrm{Pb}$ paleoproterozoicas em zircões: $2016 \pm 26 \mathrm{Ma}, 2109 \pm 8 \mathrm{Ma}$ e $2393 \pm 110$ Ma (Santos, Nutman, Brito Neves, 2004; Brito Neves et al., 2001b). Os gnaisses aluminosos também apontam idades paleoproterozoica com determinações geocronológicas $\mathrm{U} / \mathrm{Pb}$ em zircões magmáticos de metavulcânicas (2126 \pm 26 Ma; Santos, Nutman, Brito Neves, 2004) e de metavulcanoclásticas ( 2200 a 1950 Ma; Santos, Nutman, Brito Neves, 2004).

O TAM na área estudada é limitado a norte com o Terreno Alto Pajeú (TAP) por Zonas de cisalhamento 


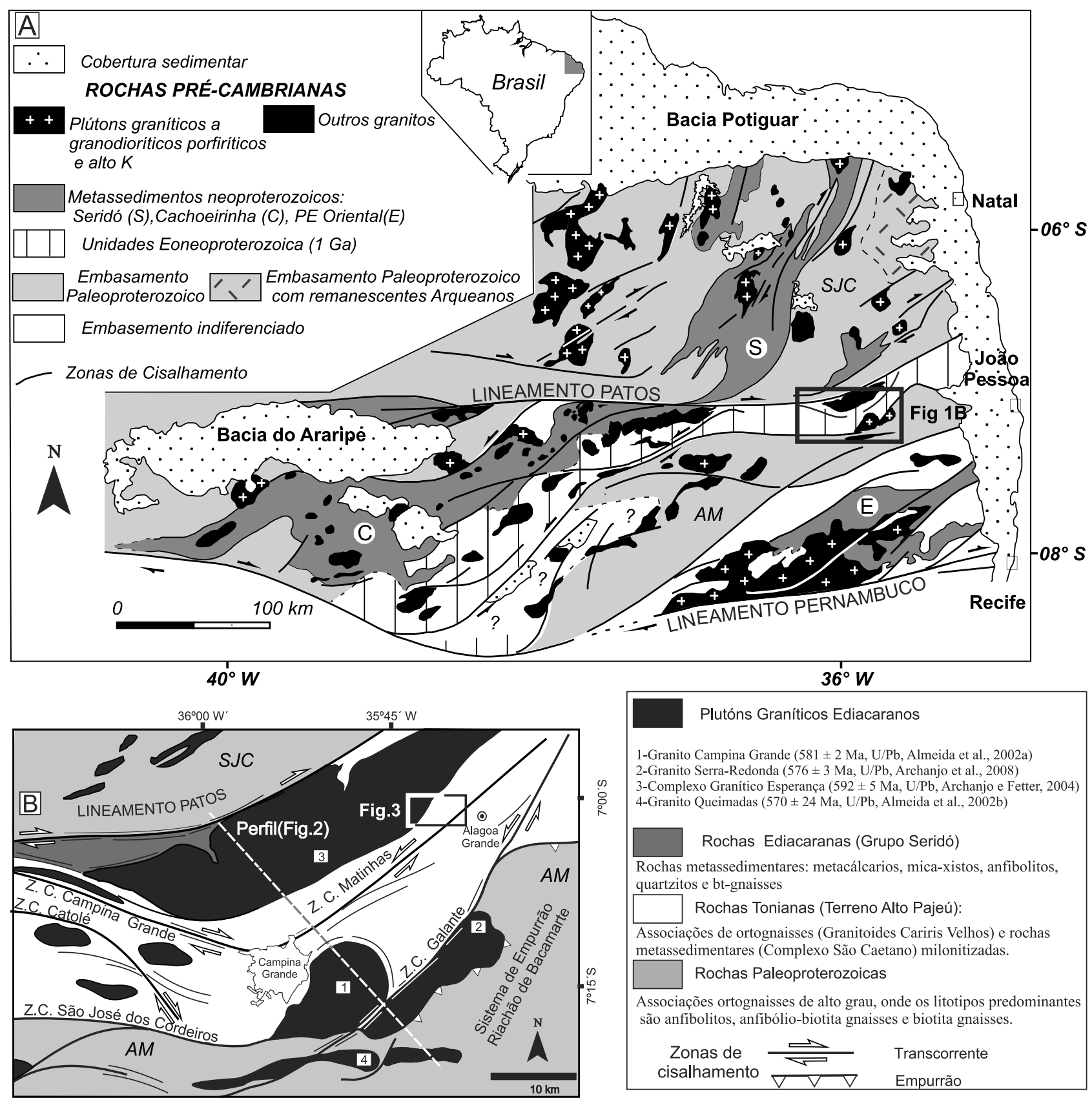

Figura 1. A. Contexto geológico e geotectônico regional da Província Borborema (modificado de Archanjo e Fetter, 2004). B. Principais zonas de cisalhamento regionais e contexto geológico e localização da secção geológica regional (Figura 2) e do mapa geológico da área estudada (Figura 3). $\mathbf{A M}=$ Alto Moxotó e SJC = São José do Campestre. 
transcorrentes e a sudeste pelo Sistema de Empurrão Riachão do Bacamarte.

$\mathrm{Na}$ área estudada o Terreno Alto Moxotó (TAM), principalmente na porção sudeste, apresenta predomínio de foliações NE-SW de médio ângulo e lineações dispersas com concentração máxima no quadrante SE (Figura 2), diferente do padrão estrutural observado próximo a zonas de cisalhamento de alto ângulo (Z. C. Galante, Matinhas etc.).

O Terreno Alto Pajeú é composto por sequências de rochas metassedimentares e metavulcano-sedimentares e metagranitoides de idades tonianas. Na região estudada, o limite norte do TAP é balizado pelo Lineamento Patos que o separa das rochas do domínio setentrional da Província Borborema. Apresenta predomínio de foliações NE-SW com lineações direcionais de baixa obliquidade (Figura 2), sendo que este padrão é muito semelhante ao observado nas zonas de cisalhamento de alto ângulo (Z. C. Galante e Matinhas). Adicionalmente ocorrem plútons intrusivos relacionados ao evento brasiliano. A Figura 3 apresenta um mapa geológico simplificado da região onde foi realizado o perfil sistemático com a obtenção das OPFs nos Metagranitoides Cariris Velhos.
A seguir serão discutidas as duas principais associações litológicas que compõem o TAP, juntamente com os principais corpos graníticos brasilianos locais.

\section{Complexo São Caetano}

A principal associação vulcano-sedimentar presente no TAP é o Complexo São Caetano caracterizado por Santos, Ferreira e Silva Júnior (2002) como uma sequência metassedimentar e metavulcanoclástica dominantemente félsica-intermediária. Os protólitos dos paragnaisses, quartzitos, (granada)- muscovita- biotita gnaisse e mica-xistos são pelitos/psamitos, grauvacas e rochas vulcanoclásticas (Santos, 1995).

No Complexo São Caetano são caracterizadas idades $\mathrm{U} / \mathrm{Pb}$ tonianas em zircões detríticos de rochas metavulcânicas (980 Ma a 964 Ma; Kozuch, 2003) e zircões magmáticos em rochas metavulcano-sedimentares $(995 \pm 12 \mathrm{Ma}$, Kozuch, 2003).

As rochas do Complexo São Caetano, na região de Alagoa Grande e Campina Grande, conforme Rodrigues e Brito Neves (2008) apresentam uma assinatura isotópica Sm-Nd com idades $\mathrm{T}_{\mathrm{DM}}$ variando de 1,37 a $2 \mathrm{Ga}$ e

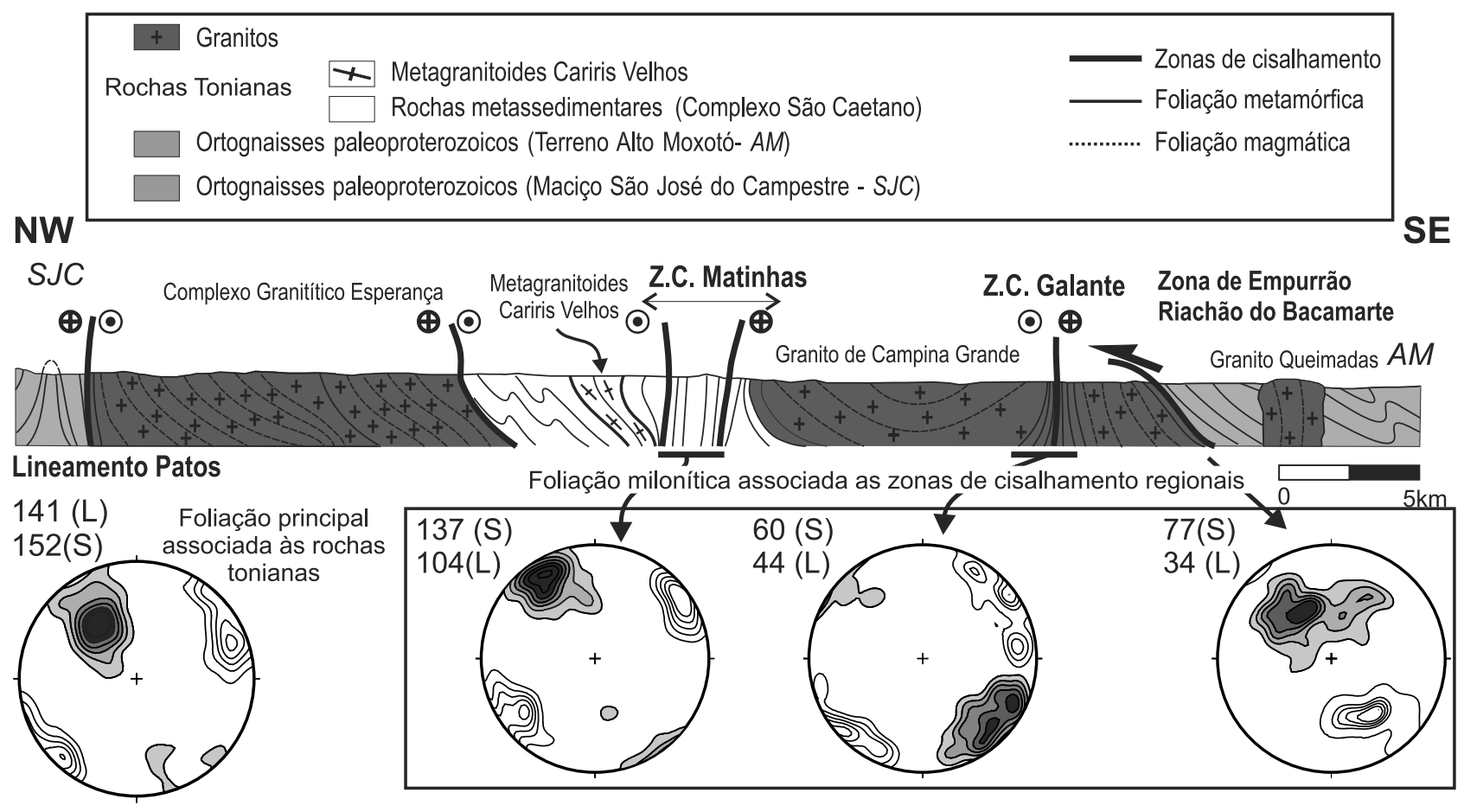

Figura 2. Perfil geológico (localização do perfil na Figura 1B) com estereogramas em semiesfera inferior com isofrequência de contagem $(2,4,6,8$ e 10) da foliação milonítica (S) e lineações de estiramento e mineral das Zonas de Cisalhamento Matinhas, Galante e Riachão do Bacamarte. Contorno em branco para lineações e preenchidos em cinza para foliações. 


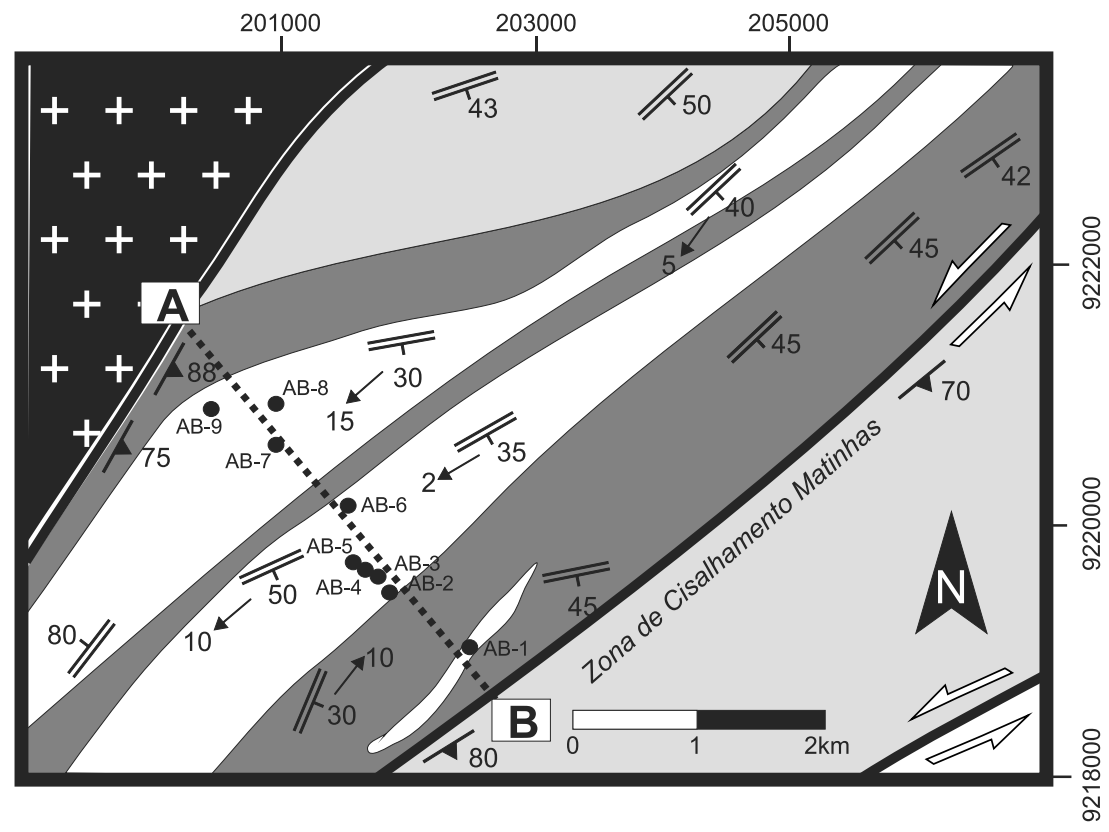

$(\mathrm{NW})$

Seção Geológica do Rio Mamanguape

A

(SE)

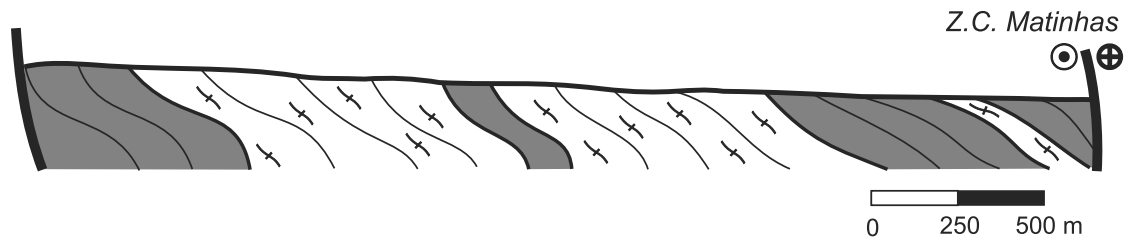

++ Complexo Granítico Esperança (ediacariano)

Rochas Tonianas

Ortognaisses (Granitoídes Cariris Velhos).

Complexo São Caetano

$\square$ Mica-xisto $\square$ biotita gnaisses e mica-xistos

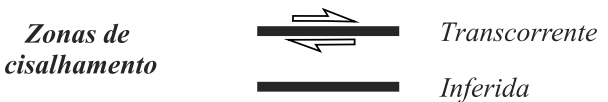

Foliação principal com mergulho medido

$\checkmark \quad$ Foliação milonítica com mergulho medido

$\rightarrow \quad$ Lineação de estriramento

Figura 3. Mapa esquemático da região estudada e perfil do Rio Mamanguape (Perfil AB). 
$\mathrm{CNd}_{(0)}$ com valores fortemente negativos. O modelamento isotópico de $\mathrm{CNd}_{(950)}$ apresenta uma variação entre 1,28 a $-10,00$, sendo que há o predomínio de valores fracamente positivos e negativos, o que também sugere a contribuição de materiais/fontes juvenis na formação das rochas deste terreno.

$\mathrm{Na}$ área estudada o Complexo São Caetano caracteriza-se pelo predomínio de um muscovita-biotita gnaisse, de granulação média a fina, geralmente milonitizado, cor cinza escura, localmente bandado (bandas quartzo-feldspáticas e biotíticas de espessura centimétrica) e às vezes granatífero. Ocorrem gradações para biotita gnaisse homogêneo, granolepidoblástico e granulação média a fina. Localmente apresenta bandamento estromático centimétrico com leucossoma granítico médio a grosso, relacionado à migmatização. Ocorrem subordinadamente níveis métricos e descontínuos de mica-xistos, quartzitos, anfibolitos e de rochas cálcio-silicáticas.

O Complexo São Caetano na Folha Campina Grande apresenta direção E-W/NE-SW devido ao forte controle estrutural das zonas de cisalhamento transcorrente sinistrais (Z. C. Matinhas e Z. C. Galante) e destrais (Z. C. Campina Grande e São José dos Cordeiros). Estas zonas de cisalhamento delimitam um complexo sistema de estruturas provavelmente consorciadas com o Lineamento $\mathrm{Pa}$ tos. Este sistema de estruturas é denominado por Rodrigues e Archanjo (2008) como "Sistema de Cisalhamento de Campina Grande". Os referidos autores apresentam que o sistema transcorrente conjugado é resultante de esforços compressivos de direção NNW-SSE, que também são responsáveis pelo cavalgamento do embasamento paleoproterozoico (Terreno Alto Moxotó) sobre o plúton granítico brasiliano da Serra Redonda.

\section{Metagranitoides Cariris Velhos}

Os Metagranitoides Cariris Velhos, conforme já mencionado, constituem uma das principais associações litológicas do Terreno Alto Pajeú. Ocorrem como corpos subordinados nas rochas do Complexo São Caetano (paralelizados à foliação milonítica - vide Figura 4A) ou como corpos mapeáveis de algumas dezenas ou centenas de metros. Caracterizam-se como um biotita augen gnaisse granítico, leucocrático, foliação de caráter milonítico a protomilonítico definida pela isorientação de minerais micáceos (principalmente biotita) e estiramento de quartzo e feldspato (Figura 4B), inequigranular e raros enclaves microgranulares máficos.

A interpretação do tipo e ambiente associado ao magmatismo dos Metagranitoides Cariris Velhos não é um consenso nos trabalhos já publicados. Os dados geoquímicos dos ortognaisses graníticos são correlacionados com diferentes ambientes tectônicos conforme o modelo interpretativo utilizado. Brito Neves et al. (2003) associam o magmatismo a ambientes similares ao de granitoides colisionais, enquanto Guimarães e Brito Neves (2005) a de granitos aluminosos do tipo-A.

As datações $\mathrm{U} / \mathrm{Pb}$ em zircões magmáticos dos Metagranitoides Cariris Velhos na Folha Campina Grande apresentam idades tonianas $(952 \pm 7 \mathrm{Ma}, 942 \pm 22 \mathrm{Ma}$ e $925 \pm$ 10 Ma; Brito Neves et al., 2001a).

Os Metagranitoides Cariris Velhos e as rochas metassedimentares do Complexo São Caetano, conforme Rodrigues e Brito Neves (2008), apresentam valores de $\mathrm{CNd}_{\text {(t) }}$ e $\mathrm{T}_{\mathrm{DM}}$ muito parecidos, o que caracteriza uma assinatura isotópica similar para estas rochas e indica uma mesma fonte crustal. Esta assinatura isotópica de Nd provavelmente reflete um período de acreção crustal relacionado ao "Evento Cariris Velhos" (Brito Neves et al., 1995). Este evento é interpretado por alguns autores como um ciclo orogenético completo, com geração de rochas e metamorfismo (Brito Neves et al., 2001a), enquanto para outros o metamorfismo é de idade brasiliana (Neves et al., 2000; Mariano et al., 2001; Neves, 2003).

No perfil do Rio Mamanguape os Metagranitoides Cariris Velhos ocorrem com direção NE-SW com caimento para SE (ângulos moderados: 30 a $50^{\circ}$ ), com contatos paralelizados aos metassedimentos do Complexo São Caetano. Ao longo do perfil, são observadas indicações cinemáticas de transporte de topo para NW (Figura 4C - Ponto AB-1), em cortes subparalelos ao plano XZ (plano paralelo à lineação de estiramento e perpendicular a foliação) que não são ideais para observação e interpretação da movimentação.

Nas terminações do perfil do Rio Mamanguape ocorrem zonas de cisalhamento de alto ângulo. Na porção NW do perfil há o contato das rochas metassedimentares do Complexo São Caetano com o Complexo magmático Esperança. Este contato é caracterizado por rochas miloníticas de alto ângulo, mas não há indicações claras da movimentação nesta região. No entanto, relativamente próximo a esta zona (Ponto AB-7) nos Metagranitoides Cariris Velhos ocorrem indicações de movimentação lateral obliqua destral (Figura 4D), dada por tramas S-C-C' associadas a uma foliação de médio ângulo ( N $35 \mathrm{E} / 50 \mathrm{SW})$ e lineação com baixa obliquidade $(\sim 220 / 10)$. Na porção SE do perfil, ocorrem milonitos associados à Zona de Cisalhamento Matinhas que apresentam indicações sinistrais de movimentação (Figura 4E).

\section{Magmatismo Granítico Brasiliano}

$\mathrm{Na}$ área estudada, ocorrem plútons brasilianos de idade Ediacarana (Complexo magmático Esperança, Campina Grande e Queimadas). 


\section{Geologia}
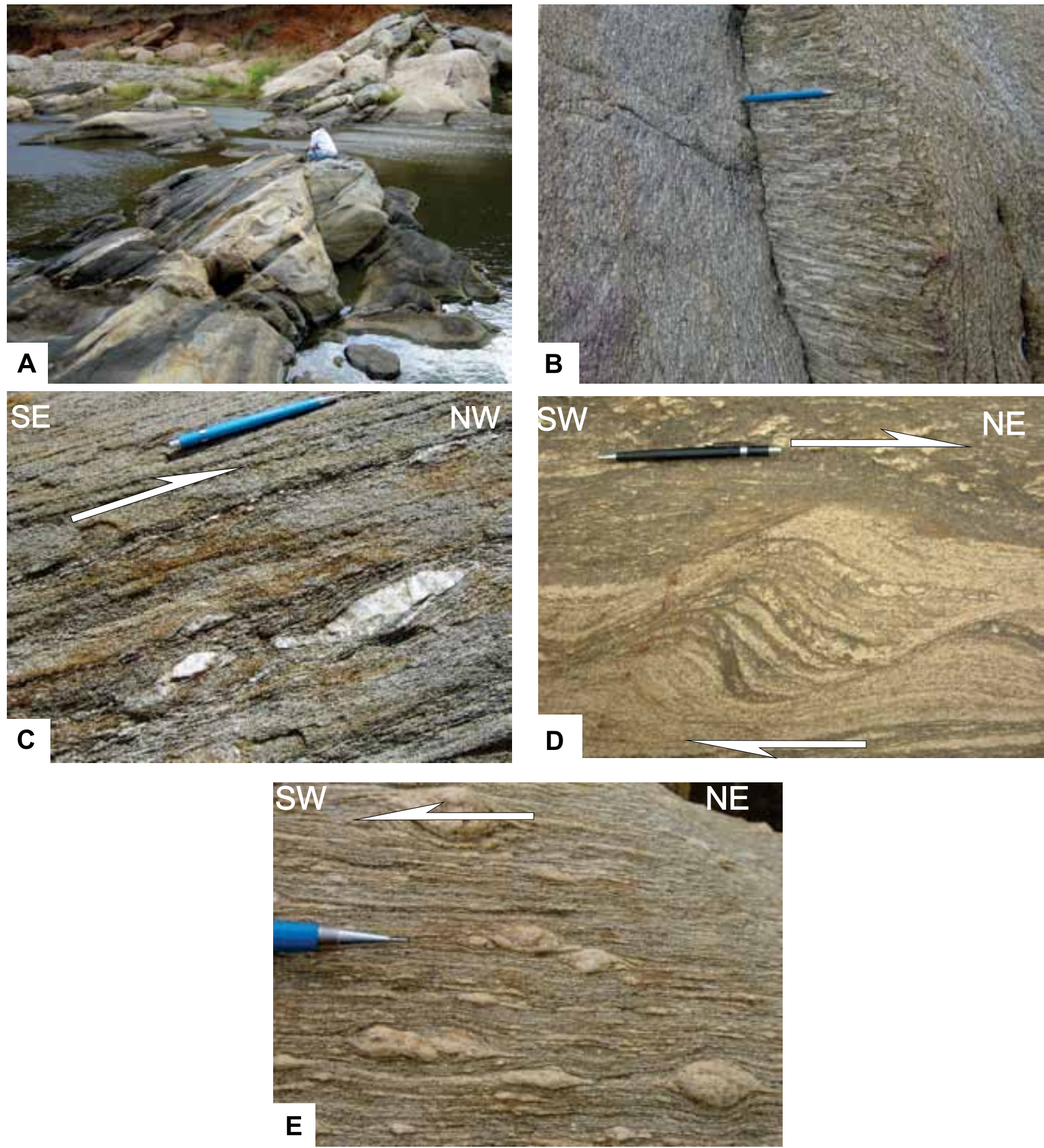

Figura 4. Rochas observadas no perfil ao longo do Rio Mamanguape (Perfil AB). A. Contato entre os Metagranitoides Cariris Velhos (rocha de cor branca a cinza clara) e rochas metassedimentares do Complexo São Caetano (biotita quartzo xisto, com cor cinza escura). B. Forte lineação de estiramento observada nos Metagranitoides Cariris Velhos (biotita augen granito gnaisse). C. Veio de quartzo sigmoidal indicando transporte de topo para NW observado em biotita gnaisse do Complexo São Caetano. D. Trama S-C-C' com indicação destral de movimentação observada em biotita augen gnaisse granítico milonítico (Metagranitoides Cariris Velhos). E. Biotita augen gnaisse granítico milonítico com feldspatos assimétricos indicando cinemática sinistral, Z. C. Matinhas. 
O Complexo magmático Esperança é formado por tonalito, sienogranito (plúton de Pocinhos), anfibólio-biotita granito porfirítico grosso e leucogranito (Archanjo e Fetter, 2004). O complexo possui uma forma de sigmoide, limitado a norte pelos milonitos de baixa temperatura do Lineamento Patos. O Complexo magmático apresenta idades $\mathrm{U} / \mathrm{Pb}$ de $592 \pm 5 \mathrm{Ma}$ (Archanjo e Fetter, 2004) no sienogranito (plúton de Pocinhos) e $581 \pm 3$ Ma no granito porfirítico grosso (Sampaio et al., 2003).

O Complexo Granítico de Campina Grande (Almeida, Guimarães, Silva Filho, 2002a), abrange dois corpos denominados de Campina Grande e Serra Redonda (Figura 1B). Eles estão situados ao longo do contato entre as rochas paleoproterozoicas e tonianas. O Granito Campina Grande destaca-se por sua forma subcircular e arredondada enquanto o de Serra Redonda pela forma tabular alongada na direção NE-SW. Estes corpos graníticos apresentam os mesmos tipos litológicos. A unidade principal consiste de um anfibólio-biotita granito porfirítico, enquanto dioritos, quartzo-dioritos e granodioritos, subordinados, ocorrem preferencialmente nas bordas das intrusões. O Granito Campina Grande apresenta idades U/Pb em zircões de $581 \pm 2$ Ma (Almeida, Guimarães, Silva Filho, 2002a), enquanto o Granito Serra Redonda apresenta idades $\mathrm{U} / \mathrm{Pb}$ de $576 \pm 3 \mathrm{Ma}$ (Archanjo et al., 2008).

O Plúton Queimadas (Almeida, Guimarães, Silva Filho, 2002b) constitui uma intrusão tabular alongada E-W intrudido entre rochas paleoproterozoicas. Caracteriza-se como uma suíte de biotita-anfibólio monzogranito. Almeida, Guimarães e Silva Filho, (2002b) apresentam a idade de $570 \mathrm{Ma} \pm 25 \mathrm{Ma}$ (U/Pb em zircões) para este corpo.

\section{MÉTODOS}

A obtenção da orientação preferencial de forma (OPF), com a análise de imagem, obedece a quatro etapas distintas (Figura 5): 1) fotografia digital de 3 (ou mais) seções aleatórias do afloramento, mas ortogonais entre si (seções mn, mo e no) ou nas seções $x y, x z$ e $y z$ (em casos específicos quando os eixos $x, y, z$ do elipsoide de deformação são conhecidos); 2) processamento da imagem, 3) determinação dos parâmetros de OPF em cada seção e 4) reconstituição do elipsoide correspondente à distribuição da subpopulação de grãos. A reconstituição da trama em 3D a

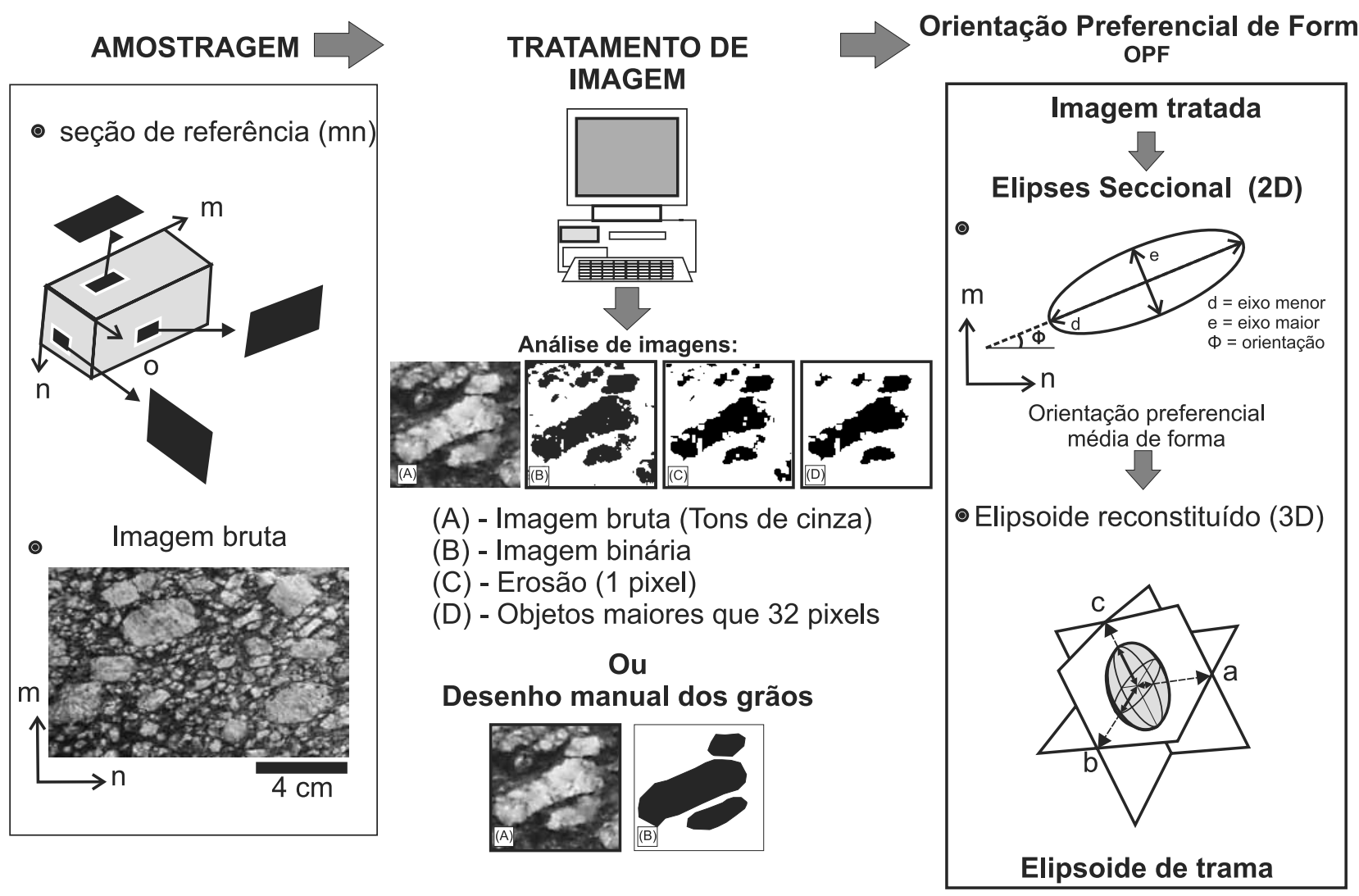

Figura 5. Aquisição da imagem, procedimentos e determinação do elipsoide de forma (ver discussão no texto). 
partir de seções 2D depende fundamentalmente do modo de ocorrência do afloramento rochoso. Este deve conter pelo menos três seções mutuamente ortogonais ou subortogonais com área de exposição igual ou maior que 2.500 $\mathrm{cm}^{2}$, no caso de rochas com granulação grossa. As seções devem ser preferencialmente planas, com bom contraste entre porfiroclastos (no caso estudado) e a matriz, ou entre os minerais máficos e félsicos. Estas condições são normalmente encontradas em cortes de estrada recentes e em pedreiras para extração de blocos. Cada face (seções $m n$, mo e no) é cuidadosamente orientada (direção/mergulho) e fotografada com uma câmera digital.

$\mathrm{O}$ estudo da (sub)-trama de porfiroclastos de feldspato é indicado quando há contraste destes com a matriz. Dependendo dos objetivos do estudo, o contorno dos porfiroclastos pode ser desenhado sobre uma folha transparente, ou diretamente no computador em programas de edição como o Adobe Photoshop ou similares, e posteriormente trabalhado como imagens binárias (preto e branco). Também podem ser utilizadas imagens brutas em tons de cinza, nas quais o contraste de tons entre a matriz e os porfiroclastos possa ser utilizado para individualizar os porfiroclastos em uma imagem binária.

$\mathrm{Na}$ conversão da imagem bruta para imagem binária são utilizados tratamentos digitais disponíveis em programas de edição de imagens que ressaltam o contraste entre a matriz e os fenocristais, como inversões de tons de cinza, ajustes de intensidade etc.

Nas imagens binárias obtidas também são aplicados outros tratamentos digitais. Um destes tratamentos, utilizado neste trabalho, consiste basicamente na erosão de 1 pixel na periferia de cada objeto obtido na conversão da imagem (no caso, representativos de porfiroclastos). Este procedimento normalmente elimina linhas de 1 pixel de comprimento, pixels isolados e estreitas "pontes" de pixels ligando objetos distintos. Posteriormente são eliminados os objetos com tamanho inferior a 32 pixels e os objetos cortados pela borda da imagem.

A determinação dos parâmetros da OPF em cada seção (imagem) foi obtida por meio da aplicação dos métodos do tensor de inércia (Launeau e Cruden, 1998) e dos Interceptos (Launeau, Bouchez, Keith, 1990; Launeau e Robin, 1996). Adicionalmente, foram confeccionados gráficos $R_{f} / \phi$ (Ramsay, 1967; Ramsay e Huber, 1983, 1987), para a visualização dos padrões de distribuição dos grãos analisados em sua orientação e forma.

Para os cálculos dos parâmetros de orientação e forma foram utilizados os programas Intercepts v. 2003 (Launeau e Robin, 2003a) e SPO v. 2003 (Launeau e Robin, 2003b).

Neste trabalho os elipsoides de forma são diretamente relacionados com elipsoides de deformação. Esta correlação é baseada nos resultados obtidos por Rodrigues e Fa- leiros (2007) que a partir de simulações computacionais de deformação progressiva aplicadas em imagens elaboradas de tramas/objetos (teóricos e reais) testam os métodos interceptos, tensor de inércia e $R_{f} / \phi$ (técnicas de Shimamoto e Ikeda, 1976 e Peach e Lisle, 1979) para quantificar a deformação. Os resultados obtidos apresentam boas correlações entre valores teóricos de razão de deformação e os obtidos pela razão de forma calculada por estes métodos. Aqui são apresentados dados que mostram que o método do tensor de inércia, originalmente desenvolvido para análise de tramas magmáticas, apresenta resultados analíticos muito similares aos do método $R_{f} / \phi$, classicamente aplicado à análise de rochas deformadas. Outros fatores que contribuem para a utilização dos métodos dos interceptos e do tensor de inércia são a facilidade e rapidez no tratamento de dados, comparados aos métodos mais tradicionais.

A reconstituição do elipsoide correspondente à distribuição da subpopulação de grãos foi realizada utilizando-se o programa ELLIPSOID (Launeau e Robin, 2003c) baseado no método do tensor quadrático de forma (Launeau e Cruden, 1998).

Nas imagens brutas e tratadas, no cálculo das elipses seccionais, cada imagem é dividida em 9 partes, gerando assim 9 resultados. Estes resultados serão combinados com os das outras imagens no cálculo do elipsoide de forma no programa ELLIPSOID (Launeau e Robin, 2003c). Assim, são geradas 729 combinações de elipsoides $(9 \times 9 \times 9=$ 729), sendo o resultado final uma média tensorial e normalizada das combinações realizadas.

A seguir serão discutidos os principais aspectos dos métodos de obtenção de OPF utilizados.

\section{Tensor de Inércia}

Este método foi desenvolvido por Launeau e Cruden (1998) originalmente para quantificação de tramas de rochas magmáticas, no entanto pode ser também utilizado para tramas de rochas metamórficas e sedimentares. A razão de forma e a orientação do eixo maior de cada grão podem ser calculadas a partir do tensor de inércia de sua forma (Launeau e Cruden, 1998). São obtidas a partir de imagens raster das seções analisadas, sendo constituídas por pixels. Se $x_{i}$ e $y_{i}$ são as coordenadas dos pixels do grão $j$ (Figura 6) e $A$ sua área superficial (igual ao número de pixels), então o tensor de inércia $\left(\mathbf{M}_{j}\right)$ de sua forma é dado pela matriz :

$$
\mathrm{M}_{j}=\left|\begin{array}{cc}
m_{x x j} & m_{x y j} \\
m_{x y j} & m_{y y j}
\end{array}\right|,
$$

onde: 
$m_{x x j}=1 / A \sum_{i}\left(x_{i}-x_{c}\right)^{2}$,

$m_{x y j}=1 / A \sum_{i}\left(x_{i}-x_{c}\right)^{2}\left(y_{i}-y_{c}\right)$,

$m_{y y j}=1 / A \sum_{i}\left(y_{i}-y_{c}\right)^{2}$,

são os componentes do tensor e $x_{c}=1 / A \sum_{i} x_{i}$ e $y_{c}=1 / A \sum_{i} y_{i}$ são coordenadas do centroide do grão.

A razão de forma do grão pode ser definida como $r=$ $\left(\lambda_{1} / \lambda_{2}\right)^{1 / 2}$ onde $\lambda_{1}$ e $\lambda_{2}$ são os autovalores de $\mathbf{M}_{j}$. Da mesma forma, a direção de máxima elongação do grão $(\Phi)$, é dada pelo maior autovetor de $\mathbf{M}_{j}$. O tamanho do semieixo maior $(a)$, e do semieixo menor $(b)$ de uma elipse representando o grão é dado por $a=0,5\left(\lambda_{1}\right)^{1 / 2}$ e $b=0,5\left(\lambda_{2}\right)^{1 / 2}$ em unidade de pixels (ou em milímetros se o tamanho do pixel é conhecido).

Para correlacionar as orientações preferenciais de forma (OPF) das populações de grãos com a OPF total, introduz-se a média do tensor de inércia de $N$ formas de grãos (Launeau, Bouchez, Keith, 1990),

$$
\mathrm{M}=1 / \mathrm{N} \sum_{j} \mathrm{M}_{j}=1 / \mathrm{N}\left|\begin{array}{ll}
\sum_{j} m_{x x j} & \sum_{j} m_{x y j} \\
\sum_{j} m_{x y j} & \sum_{j} m_{y y j}
\end{array}\right|,
$$

que efetivamente fornece uma OPF ponderada pela área de cada grão. A razão de forma média dos grãos $S R_{t}=\left(\lambda_{1} / \lambda_{2}\right)^{1 / 2}$ e sua orientação $\Phi$ são dadas pelos autovalores e autovetores máximos de $\mathbf{M}$, respectivamente. As dimensões médias $a_{t}$ e $b_{t}$ são calculadas da mesma forma.

A análise de população de grãos pelo tensor de inércia é bastante eficiente em delimitar as características geométricas de cada grão (comprimentos e orientações dos eixos menor e maior), principalmente em formas irregulares. Os dados individuais de cada grão podem ser utilizados em outros programas de cálculo da razão de deformação e de forma.

O programa SPO v. 2003 (Launeau e Robin, 2003b) também calcula a $S R_{t}$ e a orientação $\Phi$ fazendo normalização pela área dos grãos de modo que cada grão apresente o mesmo peso no cálculo.

\section{O método dos interceptos}

O método dos interceptos (Launeau e Robin, 1996) analisa camadas de objetos (fases) como uma população de linhas. A partir da seleção de fase a ser analisada, por exemplo, um intervalo específico de tons de cinza em uma imagem, é feita uma contagem dos interceptos. A base teórica do método e suas aplicações estão detalhadas em Launeau e Robin (1996).

A contagem dos interceptos é um método paramétrico de análise numérica da trama em uma imagem bidimensional. Ele consiste da determinação do número de interseções (número de pixels) entre o limite de um grão e sua matriz através da varredura completa da imagem por uma sucessão de linhas paralelas que giram entre 0 e $180^{\circ}$ (Figura 7). O resultado é representado pela projeção polar da contagem de interseções (rosa de interceptos) correspondendo a cada linha de direção $\alpha$. O alongamento máximo da rosa de interceptos corresponde à direção de menor contagem. A magnitude e a orientação da anisotropia são fornecidas pela rosa de interceptos ponderada pela área total do grão. A rosa de direções, derivada da rosa de interceptos, permite ainda vi-
A

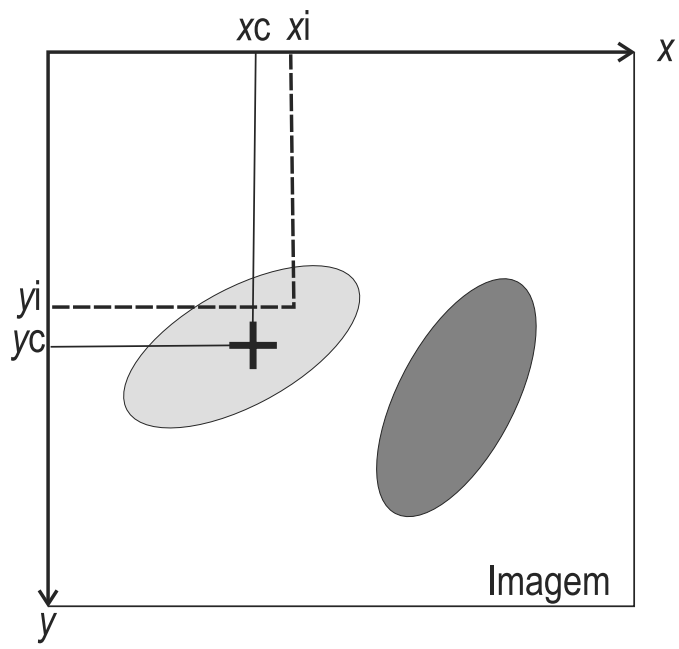

B

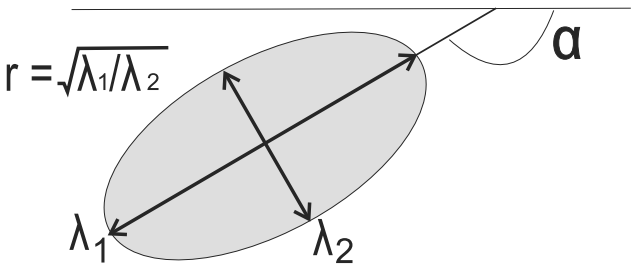

Figura 6. Elementos do componente do tensor de inércia: A. Elementos da matriz do tensor de inércia. B. Descrição tensorial do objeto cujos autoparâmetros $(\lambda 1$ e $\lambda 2)$ definem os seixos da elipse e sua orientação $(\alpha)$ no sistema de coordenadas xy. 
sualizar a geometria interna da trama através das diferentes orientações que constituem a anisotropia total.

A direção principal de alongamento da população de grãos pode ser calculada utilizando os eixos de simetria fornecidos pelos autovetores da matriz $G$ dos cosenos diretores dos interceptos (Harvey e Laxton, 1980):

$$
G=\left|\begin{array}{ll}
\sum n \alpha \cos \alpha^{2} & \sum n \alpha \cos \alpha \sin \alpha \\
\sum n \alpha \cos \alpha \sin \alpha & \sum n \alpha \cos \alpha^{2}
\end{array}\right|,
$$

onde $n$ é o número total de interceptos e $n \alpha$ o número de interceptos na direção $\alpha$. A magnitude da orientação preferencial de forma $\left(s r_{\mathrm{i}}\right)$ é fornecida pela razão entre os comprimentos médios dos interceptos $(L)$ de uma dada população computado nas direções $\alpha$ e $\alpha+\pi / 2$ onde:

$$
s r_{\mathrm{i}}=L \alpha / L \alpha+\pi / 2
$$

Para uma população de grãos circulares (isotrópicos), ou quando os grãos são anisotrópicos, porém distribuídos aleatoriamente, a rosa de interceptos ponderada possui um $s r_{\mathrm{i}}=1$; se a população de grãos anisotrópicos for perfeitamente alinhada, teríamos $s r_{\mathrm{i}}=r$, ou seja, a razão axial $(\mathrm{a} / \mathrm{c})$ média da população de grãos.

O método dos interceptos destaca-se dos demais por permitir trabalhar com imagens digitais sem um tratamento digital minucioso, como o desenho dos grãos, que na maioria dos métodos e programas se faz necessário. No processamento de imagens, geralmente, grãos isolados, perdem suas características sendo reconhecidos como um único grão. O método dos interceptos, por trabalhar a imagem como um todo consegue reconhecer a anisotropia dos grãos sem a necessidade de individualizá-los.

\section{Cálculo de elipsoides a partir das elipses de três seções perpendiculares: método do tensor quadrático de forma}

Quando uma seção bidimensional de análise é grande o bastante para representar a distribuição de uma população de grão, um conjunto de seções paralelas de uma amostra deve fornecer exatamente a mesma anisotropia, tanto em dimensão quanto em orientação (caso contrário, um grande número de seções deve ser analisado). A partir dos tensores quadráticos bidimensionais de uma amostra calcula- dos em três seções ortogonais, os coeficientes resultantes podem ser combinados para calcular o tensor quadrático tridimensional do elipsoide correspondente (Launeau e Cruden, 1998). Este método foi introduzido na geologia estrutural por Shimamoto e Ikeda (1976) para a reconstrução do elipsoide de forma (3-D) a partir dos parâmetros de forma (orientação e grau de anisotropia) medidos em três planos ortogonais entre si. O método foi recentemente generalizado para 3 ou mais planos com orientação qualquer (Robin, 2002). Para efetuar a reconstrução foi escrito um programa em Visual Basic, ELLIPSOID, que calcula o melhor elipsoide passando por três ou mais elipses caracterizadas por sua razão axial (eixo longo e curto da elipse; $\mathrm{sr}=\mathrm{a} / \mathrm{b})$ e orientação $(\varphi)$ do eixo longo (a).

Um elipsoide por ser descrito por uma equação quadrática e a correspondente matriz de forma quadrática. A equação geral do elipsoide, em um sistema de coordenadas próprio (de eixos $\mathrm{x}, \mathrm{y}$ e $\mathrm{z}$ ), pode ser expressa pela equação quadrática:

$s_{x x} x_{1 I} x_{11}+s_{y y} x_{2} x_{2}+s_{z z} x_{3} x_{3}+2 s_{y z} x_{2} x_{3}+2 s_{x z} x_{I} x_{3}+2 s_{x y} x_{T} x_{2}=1$,

onde $\mathrm{x}_{1}, \mathrm{x}_{2}$ e $\mathrm{x}_{3}$ são as coordenadas de um ponto sobre $\mathrm{o}$ elipsoide, na forma matricial: $\mathrm{X}^{\mathrm{t}} \mathrm{SX}=1$, onde $\mathrm{X}$ é a matriz coluna das coordenadas de um ponto sobre o elipsoide, $\mathrm{X}^{\mathrm{t}} \mathrm{a}$ sua transposta e $\mathrm{S}$ a matriz de forma simétrica $3 \times 3$. Quando as dimensões do sistema de coordenadas são conhecidas, o tensor de forma quadrático de uma seção xy pode ser escrito como:

$$
\mathrm{S}_{x y}=\left|\begin{array}{ll}
S_{x y} & S_{x y} \\
S_{x y} & S_{x y}
\end{array}\right|=R_{x y}^{t} \quad \mathrm{x}\left|\begin{array}{cc}
1 / a_{x y}^{2} & 0 \\
0 & 1 / b_{x y}^{2}
\end{array}\right| \times \mathrm{R}_{x y},
$$

onde $\mathrm{R}_{x y}=\left|\begin{array}{cc}\cos \psi_{x y} & -\operatorname{sen} \psi_{x y} \\ \operatorname{sen} \psi_{x y} & \cos \psi_{x y}\end{array}\right|$.

As outras duas seções mutuamente ortogonais $x z$ e $y z$ fornecem, respectivamente, os coeficientes $\mathrm{s}_{x x}, \mathrm{~s}_{x z}, \mathrm{~s}_{z z}$ e $\mathrm{s}_{y y}$, $\mathrm{s}_{y z}, \mathrm{~s}_{z z}$ de tal forma que,

$$
\mathrm{S}=\left|\begin{array}{lll}
S_{x x} & S_{x y} & S_{x z} \\
S_{x y} & S_{y y} & S_{y z} \\
S_{x z} & S_{y z} & S_{z z}
\end{array}\right|=R_{v}^{t} \mathrm{x}\left|\begin{array}{ccc}
1 / A^{2} & 0 & 0 \\
0 & 1 / B^{2} & 0 \\
0 & 0 & 1 / C^{2}
\end{array}\right| \times \mathrm{R}_{v},
$$

em que,

$$
R_{v}=\mid \begin{gathered}
\cos \alpha \cos \psi-\sin \alpha \cos \theta \cos \psi \\
\sin \alpha \cos \psi-\cos \alpha \cos \theta \cos \psi \\
\sin \theta \sin \psi
\end{gathered}
$$

$-\cos \alpha \sin \psi-\sin \alpha \cos \theta \cos \psi$
$-\sin \alpha \sin \psi+\cos \alpha \cos \theta \cos \psi$ $\sin \theta \cos \psi$ $\sin \alpha \sin \theta$

$-\cos \alpha \sin \theta$

$\cos \theta$ 


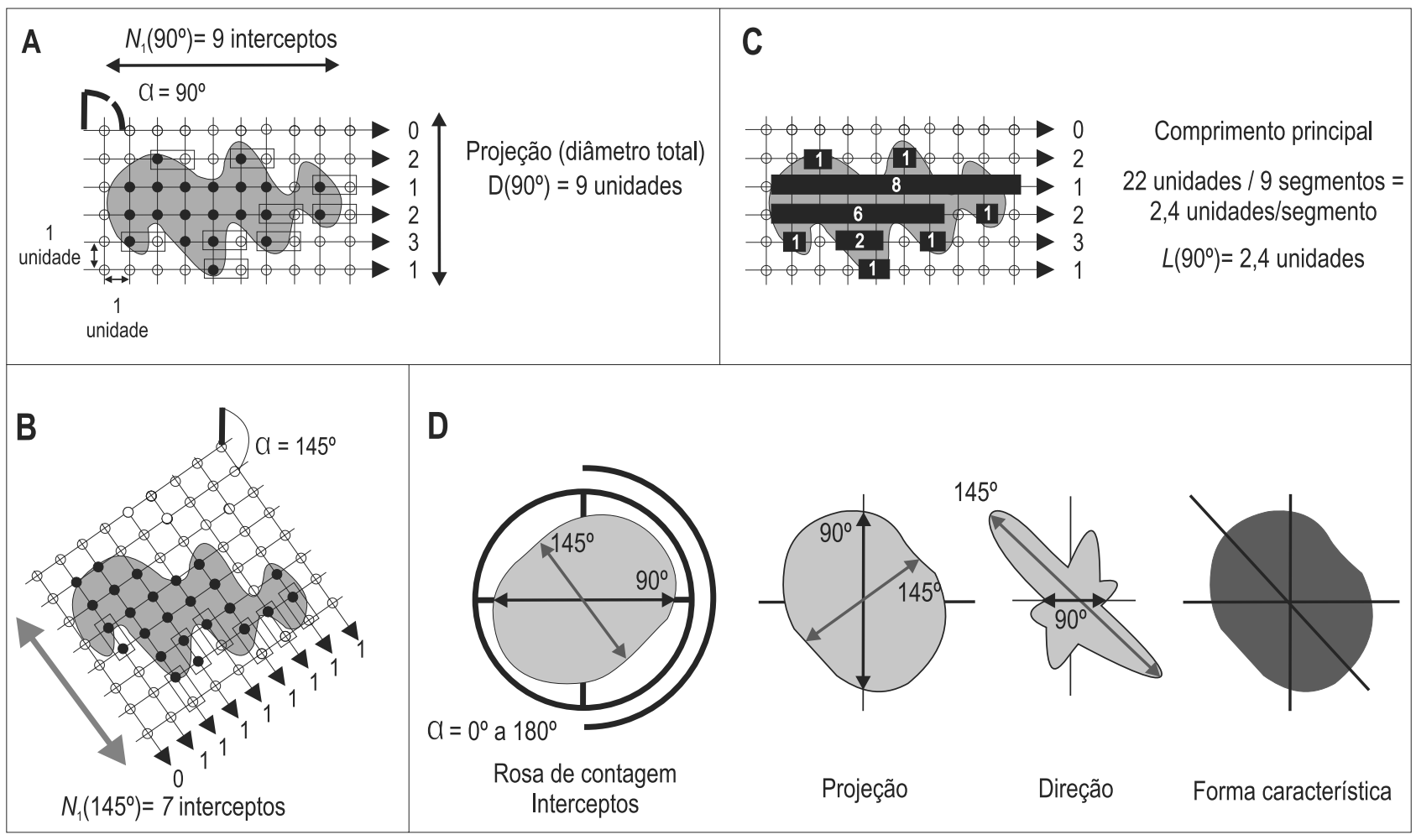

Figura 7. Determinação da anisotropia pela contagem de interceptos. A. Malha de contagem de interceptos orientada a $90^{\circ}$ em relação a um objeto (área sombreada). B. Malha de contagem de interceptos orientada a $145^{\circ} \mathrm{em}$ relação a um objeto. A análise de pontos é materializada por círculos vazados (fora do objeto) e preenchidos (interior do objeto). Para várias linhas regularmente espaçadas, paralelas à direção $\alpha$, o número de interceptos é N1 $(\alpha)$. C. Malha de contagem de interceptos na direção $90^{\circ}$ e definição do comprimento principal (valor direcional). D. Diagramas em rosáceas de contagem, com projeção do diâmetro total, direção e forma característica. Modificado de Launeau e Robin (1996).

e , $\alpha, \theta$ e $\psi$ são os ângulos de Euler correspondendo ao azimute, direção e mergulho do elipsoide com comprimentos $\operatorname{dos}$ eixos $\mathrm{A} \geq \mathrm{B} \geq \mathrm{C}$.

A matriz $S$ é denominada "matriz de forma" do elipsoide, contudo, como seus valores principais são funções inversas dos respectivos comprimentos dos eixos do elipsoide, a matriz $S$ também é conhecida como "matriz de forma inversa". Para que a equação quadrática represente um elipsoide, antes que um hiperboloide ou um cilindro elíptico, os autovalores de $S(s x>s y>s z$ ) devem ter valores positivos. As direções dos semieixos longo, intermediário e curto do elipsoide são equivalentes aos autovetores de $S$, e suas dimensões $A, B$ e $\mathrm{C}$ dadas por:

$$
\mathrm{A}=\frac{1}{\sqrt{S_{x}}}, \mathrm{~B}=\frac{1}{\sqrt{S_{y}}} \text { e } \mathrm{C}=\frac{1}{\sqrt{S_{z}}},
$$

As propriedades matemáticas do tensor de forma quadrático são as mesmas de outras grandezas físicas, tais como a anisotropia de suscetibilidade magnética (ASM), a deformação interna (strain) etc. A comparação entre a orientação preferencial de forma (OPF) e a ASM torna-se, deste modo, internamente consistente. O programa ELLIPSOID fornece a orientação das direções principais do elipsoide de forma e os seus parâmetros escalares. O programa fornece ainda um "índice de incompatibilidade" entre a medida de uma seção e o elipsoide calculado. Este parâmetro é determinado em cada seção e permite, eventualmente, eliminar do cálculo as seções ou subpopulações fortemente incompatíveis. A compatibilidade entre as elipses seccionais (2-D) e o elipsoide calculado (3-D) é dada pelo parâmetro $\sqrt{F}(\%)$. O ajuste das elipses seccionais a um elipsoide (ou hiperboloide) é justificado quando $\sqrt{F}(\%)$ é pequeno $(\leq 10)$ e ideal quando $\sqrt{F}(\%)=0$. O programa ELLIPSOID calcula os mesmos parâmetros utilizados na ASM, a saber:

- $\mathrm{P}($ grau de anisotropia $)=\mathrm{A} / \mathrm{C}$,

- P' (anisotropia corrigida $)=\exp \left[2\left(l_{1}^{2}+l_{2}^{2}+l_{3}^{2}\right)\right]$, 
onde $l \mathrm{n}=\ln (\mathrm{A}, \mathrm{B}$ ou $\mathrm{C} / l)$ e $l=(\mathrm{A} \times \mathrm{B} \times \mathrm{C}) / 3$;

- $\mathrm{L}=\mathrm{A} / \mathrm{B}$ (lineação);

- $\mathrm{F}=\mathrm{B} / \mathrm{C}$ (foliação);

- T $($ parâmetro de forma $)=\left[2\left(\ln b_{2}-\ln b_{3}\right) /\left(\ln b_{1}+\ln b_{3}\right)\right]-1$.

Onde: $\mathrm{T}=1$, se $\mathrm{A}=\mathrm{B}>\mathrm{C}$ planar ou oblato; $\mathrm{T}=0$, se $\mathrm{A}>\mathrm{B}>\mathrm{C}$ plano-linear ou neutro; $\mathrm{T}=-1$, se $\mathrm{A}>\mathrm{B}=\mathrm{C}$ linear ou prolato.

\section{RESULTADOS OBTIDOS}

A caracterização da petrotrama mineral foi realizada em um perfil geológico localizado no Rio Mamanguape, nas proximidades do município de Alagoa Grande (Figuras 2 e 3), onde ocorrem excelentes exposições dos Ortognaisses Cariris Velhos, sendo analisado um total de nove afloramentos. As rochas analisadas tratam-se, no geral, de ortognaisses de composição granítica, em que o contraste de porfiroclastos de feldspato na matriz é acentuado. Em todos os casos analisados foram utilizadas três seções ortogonais aleatórias (seções $m n$, mo e no) que apresentam imagens com áreas variando de $2.500 \mathrm{~cm}^{2}$ a $5.000 \mathrm{~cm}^{2}$.

A Figura 8 apresenta as imagens analisadas do afloramento 1-AB (seções ortogonais $m n$, mo e no), juntamente com o produto do processamento digital, além dos gráficos $R_{f} / \phi$ dos grãos delimitados nas imagens tratadas das seções analisadas. Ressalta-se que o tratamento de imagem

\section{Seção mo}
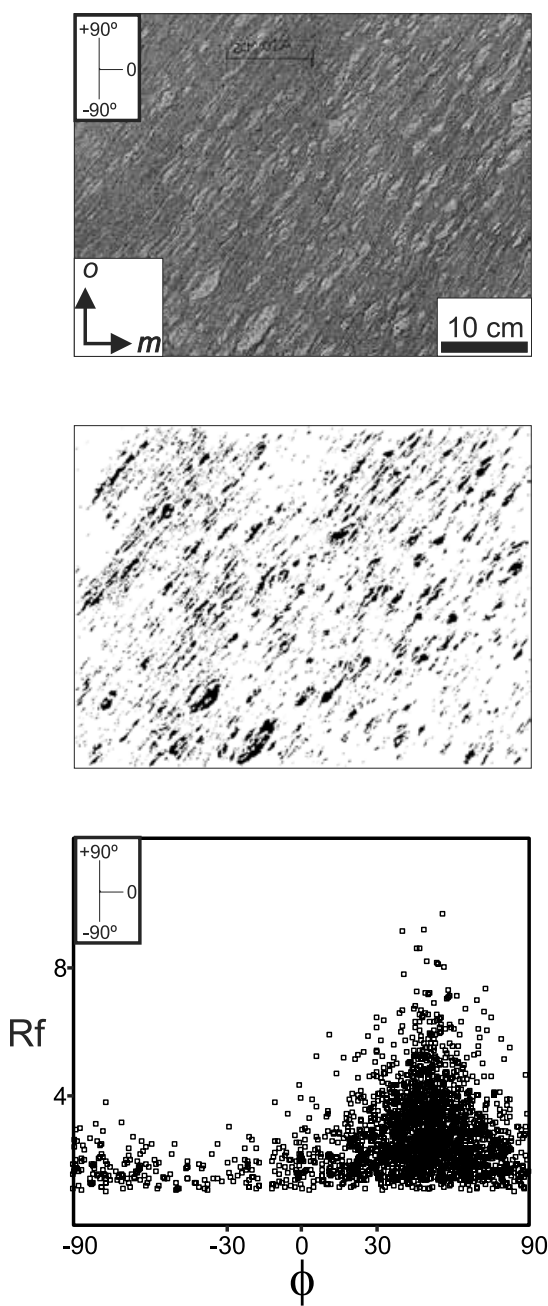

Seção no Imagem bruta
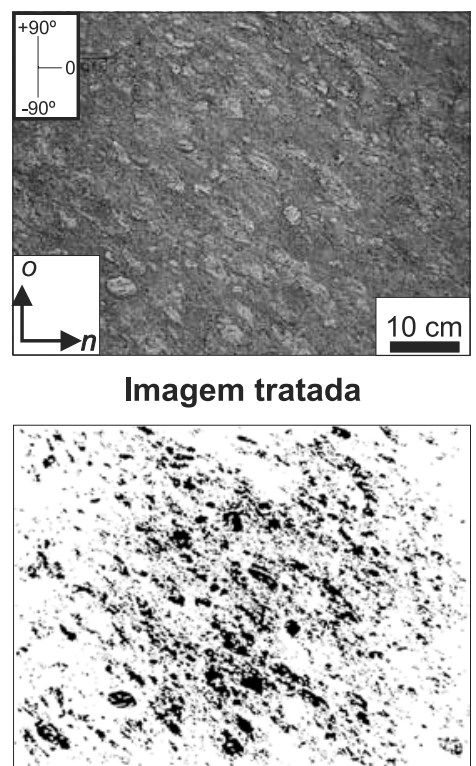

Gráficos Rf/ $\phi$

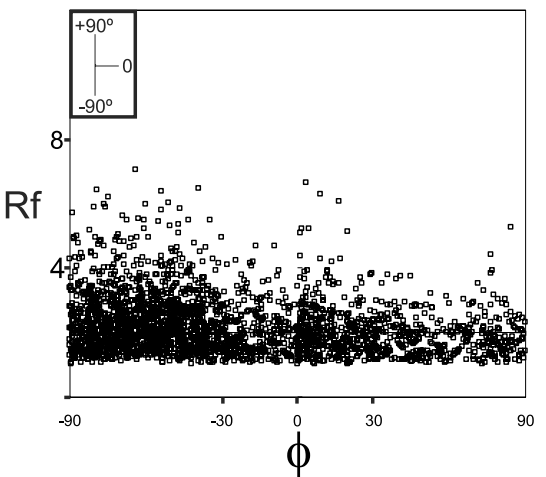

Seção $m n$
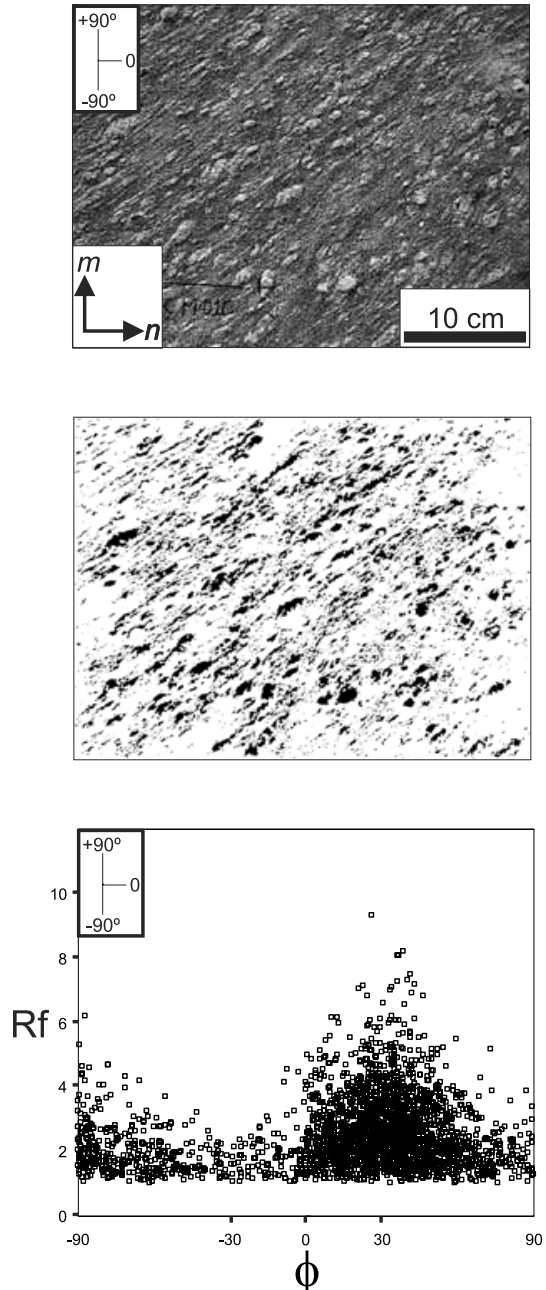

Figura 8. Seções (sub)-ortogonais da estação $A B 1$, com imagens brutas e tratadas. A distribuição das razões axiais (Rf) e orientação $(\Phi)$ dos eixos longos dos porfiroclastos obtidos por tratamento de imagem mostram uma nítida orientação nos planos mn e mo. 
apresenta uma série de limitações para individualizar grãos, existindo uma diferença significativa entre os produtos gerados pela análise de imagem e os produtos gerados pela individualização de grãos manual. No entanto, estas diferenças não comprometem o resultado qualitativo final, conforme observado em Rodrigues, Archanjo e Launeau (2009) que utilizaram diferentes métodos e imagens (brutas, tratadas e de grãos desenhadas) para obter a orientação preferencial de forma (OPF) em rochas graníticas. As OPFs obtidas por Rodrigues, Archanjo e Launeau (2009) apresentam geometria e parâmetros de forma bem semelhantes entre si, mas com graus de anisotropias diferentes.

O gráfico $R_{f} / \phi$ (Figura 8) fornece o padrão de distribuição dos porfiroclastos de feldspato da seção analisada no afloramento. Este gráfico relaciona a forma do objeto $\left(\mathrm{R}_{\mathrm{f}}=\right.$ eixo menor/eixo maior) com a sua orientação $(\phi)$ no referencial adotado (origem $=0^{\circ}$ ). Se os pontos correspondentes à orientação dos eixos longos dos porfiroclastos de feldspato se dispersam sem uma orientação preferencial (aleatoriamente), podemos afirmar que a distribuição tende à isotrópica na seção considerada. Por outro lado, se os pontos tendem a agrupar, concluímos que a população apresenta uma orientação preferencial. A variação de $\mathrm{R}_{\mathrm{f}}$, por outro lado, indica o grau de homogeneidade das razões axiais da população. As distribuições simétricas ou assimétricas de $\mathrm{R}_{\mathrm{f}} \mathrm{em}$ relação à orientação média $\left(\phi_{1}\right)$ indicam a existência de orientações iniciais $\left(\phi_{0}\right)$ preexistentes nas tramas analisadas, conforme Lisle (1985). As distribuições simétricas são associadas a tramas sem orientações iniciais, enquanto as assimétricas a tramas previamente orientadas.

Outra característica que foi observada nos gráficos $R_{f} / \phi$ refere-se à distribuição normal ou em forma de gota dos valores de $\mathrm{R}_{\mathrm{f}}$ A distribuição normal de valores de $\mathrm{R}_{\mathrm{f}}$ é indicativa de razões iniciais dos objetos/grãos (Ri) maiores que as razões de deformações $\left(\mathrm{R}_{\mathrm{s}}\right)$ além disso, a orientação dos objetos/grãos incipiente a moderada, sendo estas características associadas a baixas taxas de deformação. A distribuição em forma de gota indica que as razões iniciais dos objetos/ grãos $\left(\mathrm{R}_{\mathrm{i}}\right)$ são menores que as razões de deformações $\left(\mathrm{R}_{\mathrm{s}}\right)$ e a orientação dos objetos/grãos moderada a forte, características associadas a taxas de deformação elevadas.

Os gráficos $R_{f} / \phi$ apresentados na Figura 8 , obtidos no afloramento AB-1, mostram que: 1) as razões axiais da população de feldspato variam principalmente entre $1 \leq R_{f} \leq$ 4, podendo localmente chegar a $\mathrm{R}_{\mathrm{f}}=10$ nas faces $m n$ e $m o$; 2 ) as faces $m n$ e $m o$ apresentam uma nítida orientação preferencial de forma, enquanto na face no há uma dispersão maior das orientações. Este tipo de informação é útil para entender os eventuais problemas relacionados a OPFs anômalas, o que permite, dependendo do caso, reamostrar a face ou mesmo o afloramento.
Também na Figura 8 observa-se que os padrões de distribuições de $\mathrm{R}_{\mathrm{f}}$ em relação à orientação média $\left(\phi_{1}\right)$ nas seções analisadas ( $m n$, mo e no) são simétricos e com distribuição normal (indicativa de baixas taxas de deformação e $\mathrm{R}_{\mathrm{i}}>\mathrm{R}_{\mathrm{s}}$ ). $\mathrm{O}$ comportamento observado indica que não há uma orientação prévia da trama mineral analisada e também que os objetos/grãos analisados apresentam formas parcialmente deformadas e orientadas.

As seções analisadas (seções $m n$, mo e no) dos outros afloramentos estudados apresentam distribuição de $\mathrm{R}_{\mathrm{f}}$ semelhantes às observadas nos gráficos $R_{f} / \phi$ apresentados na Figura 8 (distribuição normal e simétrica).

\section{Elipsoides obtidos}

As orientações preferenciais dos eixos A (lineação mineral/estiramento) e C (indicativa do polo da foliação) dos elipsoides de forma/deformação calculados nos afloramentos estudados, juntamente com os parâmetros de forma (T), grau de anisotropia (P), razão de forma (SR) e parâmetro de ajuste das seções das elipses no elipsoide $(\sqrt{F} \%)$ são apresentados na Tabela 1. Também nesta tabela os valores de orientação dos eixos A (lineação mineral/estiramento) e C (polo da foliação) podem ser comparados com os valores medidos em campo. A Figura 9 apresenta a plotagem em estereogramas das orientações dos eixos A, B e C dos elipsoides de forma/deformação obtidos juntamente com os co-

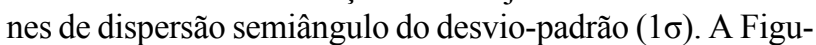
ra 10 compara os parâmetros de forma e grau de anisotropia obtidos nos diferentes tratamentos realizados.

As orientações preferências de forma (OPF) obtidas a partir da análise da petrotrama mineral para os afloramentos estudados apresentam orientações bem parecidas, mesmo quando se utilizam técnicas diferentes e imagens diferentes (brutas ou processadas). As orientações dos eixos A, B e C, no geral apresentam cones de dispersão com semiângulos do desvio-padrão $(1 \sigma)$ com ângulos pequenos, o que denota concentrações bem delimitadas de dados. As exceções para este padrão são os eixos $\mathrm{A}$ e $\mathrm{B}$ do afloramento AB-2, que apresentam os cones de dispersão com semiângulos do desvio-padrão maiores (entre $35^{\circ}$ e $55^{\circ}$ ) distribuídos ao longo do circulo máximo representativo da foliação. Este comportamento do afloramento AB-2 é associado a uma trama mineral essencialmente planar (tectonito S, Turner e Weiss, 1963). Os afloramentos analisados também obtiveram valores de $\sqrt{F}$ (\%), parâmetro de ajuste das seções das elipses no elipsoide, com valores dentro do ideal ou seja, menor que $15 \%$.

As OPFs calculadas apresentam forte orientação do eixo $\mathrm{C}$, que reflete o polo da foliação, que tem direção NE-SW, com caimento para SE ( N55E/35 SE). As OPFs obtidas são compatíveis com os dados estruturais coletados 
Tabela 1. Parâmetros do elipsoide de forma dos afloramentos analisados calculados a partir de imagens brutas e tratadas de seções ortogonais de afloramento calculados pelos métodos dos interceptos e tensor de inércia. $\mathbf{T}=$ Parâmetro de forma, $\mathbf{P}=$ grau de anisotropia, $\mathbf{S} \mathbf{R}=$ razão de forma, $\mathbf{A}$ e $\mathbf{C}=$ pólos da lineação mineral e foliação, respectivamente. Entre parênteses o semiângulo do desvio-padrão $(1 \sigma)$ em volta do tensor principal; e $\sqrt{\mathbf{F}}(\%)=$ parâmetro de ajuste das seções das elipses no elipsoide (< 15\%).

\begin{tabular}{|c|c|c|c|c|c|c|}
\hline & $\mathbf{T}$ & $\mathbf{P}$ & SR & A & C & $\sqrt{F}$ \\
\hline \multicolumn{7}{|l|}{ AB-01 } \\
\hline Interceptos -Imagem bruta & 0,041 & 2,338 & 2,31 & $065 / 19(3,8)$ & $299 / 60(5,1)$ & 3,8 \\
\hline Interceptos -Imagem tratada & 0,159 & 1,831 & 1,818 & $065 / 17(4,6)$ & $305 / 58(6,3)$ & 3,2 \\
\hline Tensor de Inércia -Imagem tratada & 0,555 & 2,882 & 2,691 & $065 / 17(5,1)$ & $305 / 58(6,9)$ & 3,5 \\
\hline Orientação obtida em campo & $\mathrm{x}$ & $\mathrm{x}$ & $\mathrm{x}$ & $081 / 29$ & $310 / 45$ & $\mathrm{x}$ \\
\hline \multicolumn{7}{|l|}{ AB-02 } \\
\hline Interceptos -Imagem bruta & 0,723 & 1,712 & 1,638 & $075 / 16(37,4)$ & $320 / 56(5,1)$ & 3,7 \\
\hline Interceptos -Imagem tratada & 0,761 & 1,538 & 1,481 & $075 / 15(43,1)$ & $321 / 57(4,7)$ & 3,5 \\
\hline Tensor de Inércia -Imagem tratada & 0,761 & 1,538 & 1,846 & $059 / 4(55,1)$ & $322 / 58(4,4)$ & 3,3 \\
\hline Orientação obtida em campo & $\mathrm{x}$ & $\mathrm{x}$ & $\mathrm{x}$ & $088 / 23$ & $325 / 50$ & $\mathrm{x}$ \\
\hline \multicolumn{7}{|l|}{ AB-03 } \\
\hline Interceptos -Imagem bruta & 0,434 & 2,161 & 2,095 & $098 / 20(10,4)$ & $328 / 60(4,1)$ & 2,1 \\
\hline Interceptos -Imagem tratada & 0,601 & 1,661 & 1,612 & $092 / 17(14,0)$ & $326 / 62(5,5)$ & 1,7 \\
\hline Tensor de Inércia -Imagem tratada & 0,604 & 2,017 & 1,928 & $079 / 13(20,5)$ & $322 / 64(6,2)$ & 2,8 \\
\hline Orientação obtida em campo & $\mathrm{x}$ & $\mathrm{x}$ & $\mathrm{x}$ & $108 / 25$ & $332 / 55$ & $\mathrm{x}$ \\
\hline \multicolumn{7}{|l|}{ AB-04 } \\
\hline Interceptos -Imagem bruta & 0,156 & 1,866 & 1,853 & $086 / 18(7,4)$ & $325 / 58(5,9)$ & 2,8 \\
\hline Interceptos -Imagem tratada & 0,259 & 1,841 & 1,821 & $090 / 20(8,2)$ & $325 / 58(6,3)$ & 3 \\
\hline Tensor de Inércia -Imagem tratada & 0,32 & 2,362 & 2,303 & $089 / 19(9,4)$ & $324 / 59(6,5)$ & 3,3 \\
\hline Orientação obtida em campo & $\mathrm{x}$ & $\mathrm{x}$ & $\mathrm{x}$ & $089 / 25$ & $320 / 50$ & $\mathrm{x}$ \\
\hline \multicolumn{7}{|l|}{ AB-05 } \\
\hline Interceptos -Imagem bruta & $-0,074$ & 4,087 & 3,886 & $077 / 17(5,8)$ & $311 / 62(3,4)$ & 4,3 \\
\hline Interceptos -Imagem tratada & 0,072 & 1,847 & 1,838 & $080 / 18(8,4)$ & $310 / 64(4,0)$ & 3,7 \\
\hline Tensor de Inércia -Imagem tratada & 0,028 & 3,261 & 3,166 & $080 / 18(6,9)$ & $313 / 61(4,0)$ & 3,6 \\
\hline Orientação obtida em campo & $\mathrm{x}$ & $\mathrm{x}$ & $\mathrm{x}$ & $087 / 14$ & $334 / 60$ & $\mathrm{x}$ \\
\hline \multicolumn{7}{|l|}{ AB-06 } \\
\hline Interceptos -Imagem bruta & $-0,16$ & 1,98 & 1,961 & $242 / 11(4,2)$ & $344 / 48(6,1)$ & 3,1 \\
\hline Interceptos -Imagem tratada & $-0,141$ & 1,922 & 1,907 & $239 / 13(3,4)$ & $346 / 51(6,3)$ & 1,9 \\
\hline Tensor de Inércia -Imagem tratada & $-0,197$ & 2,923 & 2,834 & $242 / 11(4,1)$ & $346 / 52(6,5)$ & 3,1 \\
\hline Orientação obtida em campo & $\mathrm{x}$ & $\mathrm{x}$ & $\mathrm{x}$ & $232 / 15$ & $330 / 60$ & $\mathrm{x}$ \\
\hline \multicolumn{7}{|l|}{ AB-07 } \\
\hline Interceptos -Imagem bruta & 0,069 & 1,994 & 1,98 & $236 / 07(5,0)$ & $333 / 43(5,7)$ & 3 \\
\hline Interceptos -Imagem tratada & $-0,017$ & 1,785 & 1,778 & $238 / 05(5,7)$ & $334 / 47(5,7)$ & 2,5 \\
\hline Tensor de Inércia -Imagem tratada & 0,079 & 2,343 & 2,313 & $238 / 05(5,9)$ & $334 / 52(5,7)$ & 2,1 \\
\hline Orientação obtida em campo & $\mathrm{x}$ & $\mathrm{x}$ & $\mathrm{x}$ & $248 / 02$ & $338 / 35$ & $\mathrm{x}$ \\
\hline \multicolumn{7}{|l|}{ AB-08 } \\
\hline Interceptos -Imagem bruta & 0,001 & 1,582 & 1,579 & $243 / 05(8,1)$ & $342 / 62(11,8)$ & 2,9 \\
\hline Interceptos -Imagem tratada & $-0,16$ & 1,772 & 1,761 & $244 / 07(5,1)$ & $353 / 69(11,2)$ & 2,4 \\
\hline Tensor de Inércia -Imagem tratada & $-0,431$ & 2,233 & 2,158 & $242 / 05(5,3)$ & $347 / 69(15,8)$ & 3 \\
\hline Orientação obtida em campo & $\mathrm{x}$ & $\mathrm{x}$ & $\mathrm{x}$ & $238 / 10$ & $008 / 65$ & $x$ \\
\hline \multicolumn{7}{|l|}{ AB-09 } \\
\hline Interceptos -Imagem bruta & 0,643 & 2,188 & 2,068 & $230 / 08(16,5)$ & $331 / 52(4,5)$ & 2,1 \\
\hline Interceptos -Imagem tratada & 0,551 & 1,996 & 1,921 & $221 / 15(7,1)$ & $331 / 53(4,2)$ & 1,5 \\
\hline Tensor de Inércia -Imagem tratada & 0,294 & 5,018 & 4,62 & $220 / 18(9,7)$ & $329 / 46(5,6)$ & 2,7 \\
\hline Orientação obtida em campo & $\mathrm{x}$ & $\mathrm{x}$ & $\mathrm{x}$ & $204 / 20$ & $318 / 30$ & $\mathrm{x}$ \\
\hline
\end{tabular}




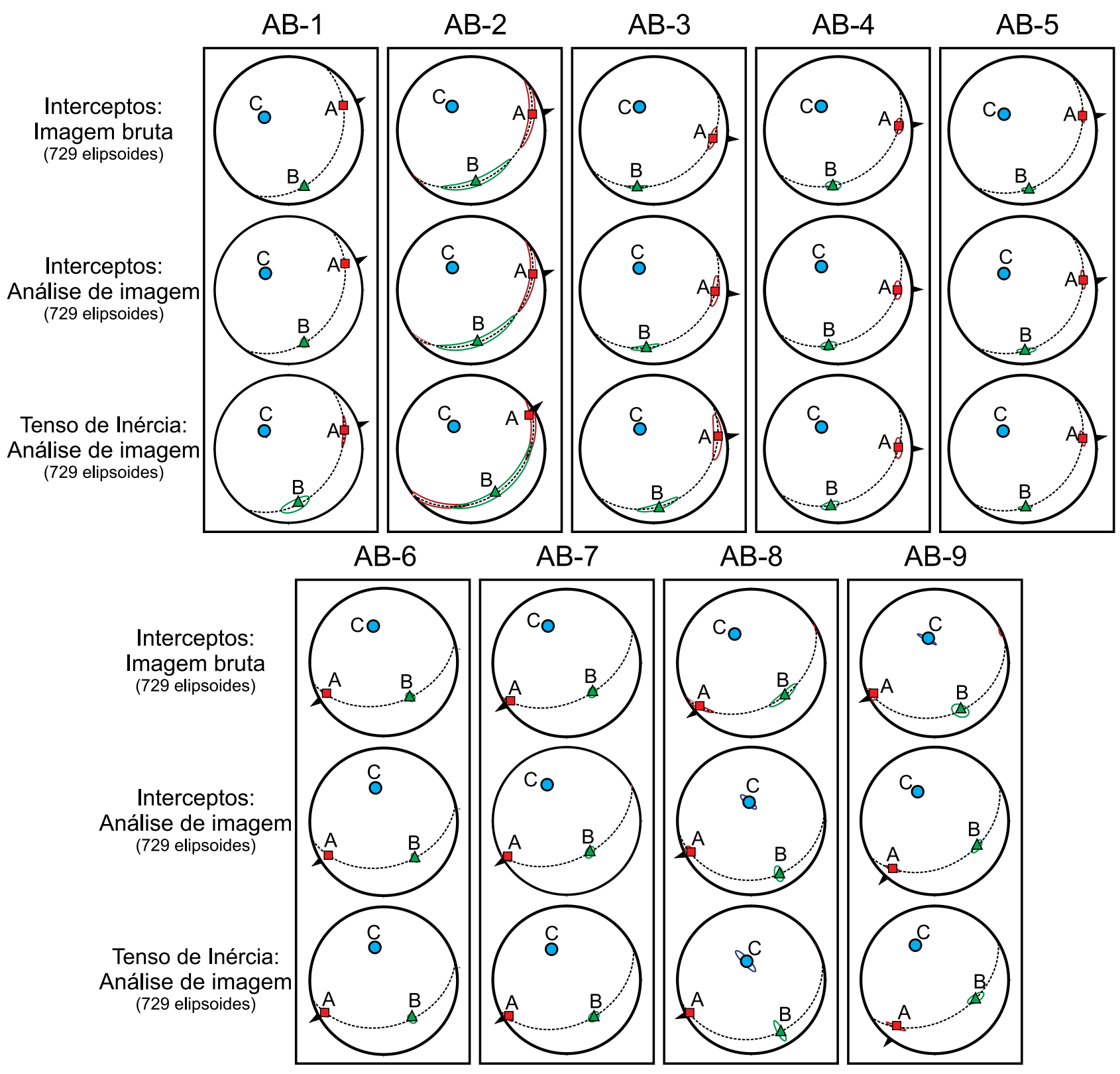

Figura 9. Orientação dos eixos ( $\mathbf{A}=$ lineação mineral, $\mathbf{B}=$ intermediário e $\mathbf{C}=$ pólo da foliação) do elipsoide de forma juntamente com os cones de dispersão semiângulo do desvio-padrão $(1 \sigma)$ dos afloramentos analisados. A maior parte dos cones de dispersão semiângulo do desvio-padrão $(1 \sigma)$ não é representada nos estereogramas, pois apresentam dispersão baixa $\left(<5^{\circ}\right)$ sendo encorbertos pela representação dos eixos.

ao longo do perfil do Rio Mamanguape (Figura 10C e Tabela 1). A orientação do eixo A que representa a lineação mineral/estiramento também apresenta comportamento similar ao observado em campo, sendo distribuída ao longo do eixo NE-SW com baixas obliquidades.

Quanto aos parâmetros calculados (P, T e SR) nota-se que os valores de $\mathrm{T}$ (parâmetros de forma) apresen- tam resultados com valores próximos entre si nos métodos e imagens utilizados (Figura 10A). Já os valores referentes ao grau de anisotropia (P) e razão de forma (SR) apresentam diferenças significativas de valores conforme os métodos e as imagens utilizadas (Figura 10A). Nota-se nos resultados obtidos que, sistematicamente para o método dos interceptos o parâmetro P (grau de anisotropia) e 
A
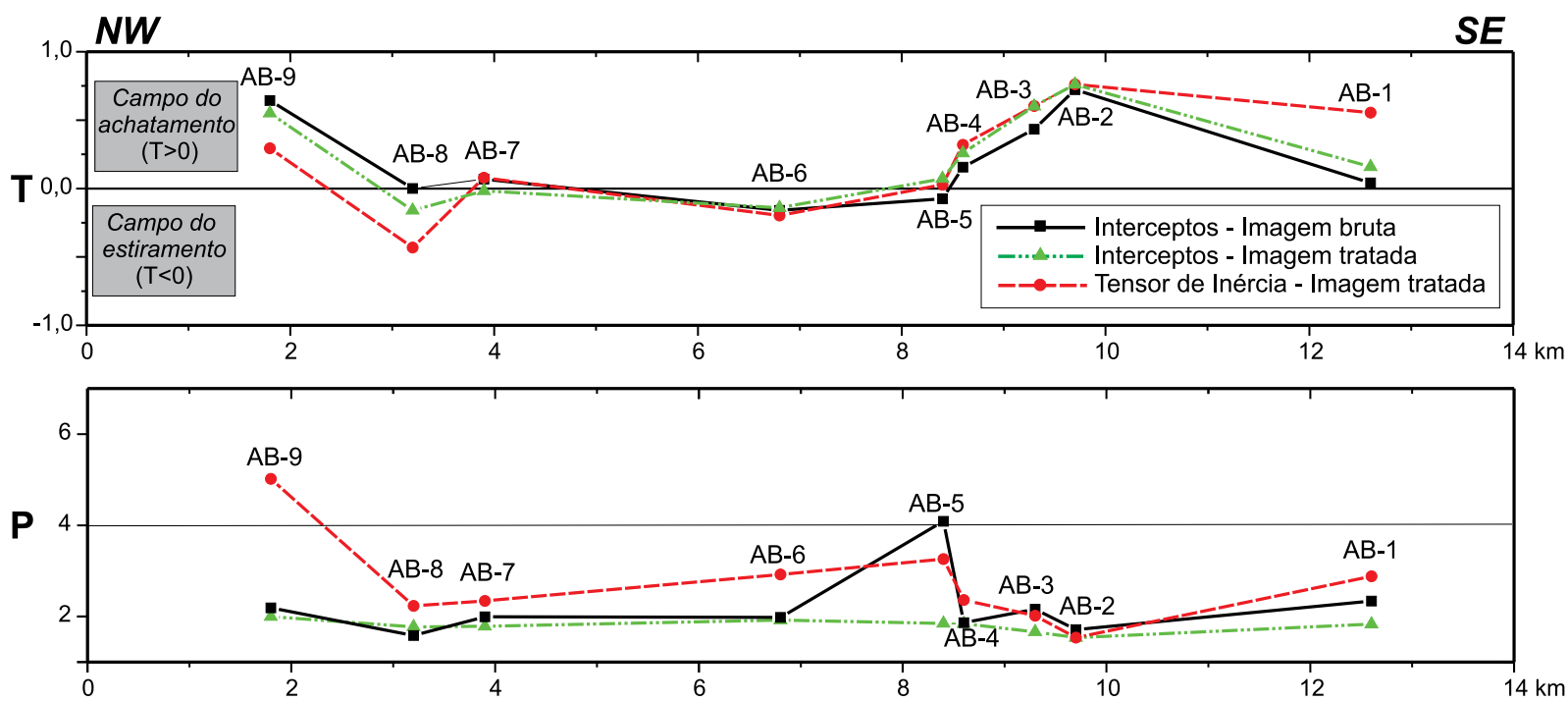

B

(NW)

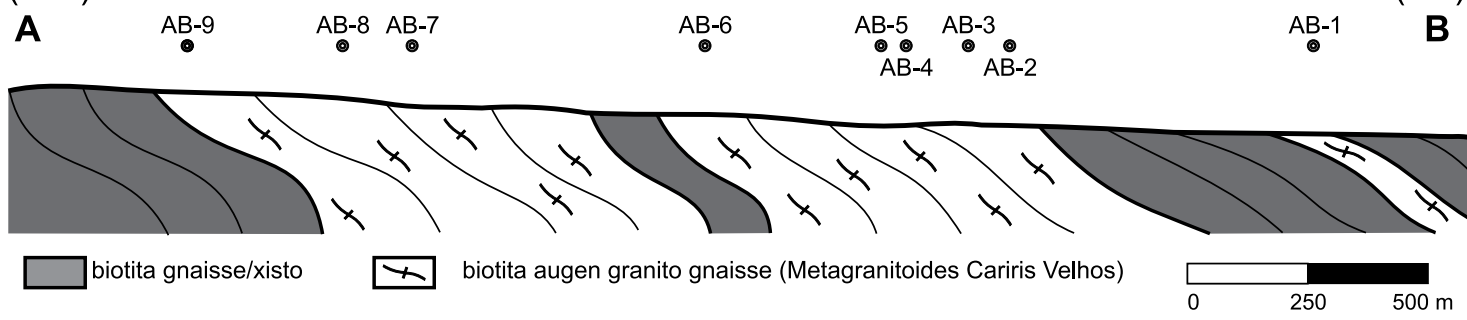

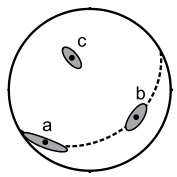

AB-9

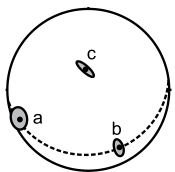

AB-8

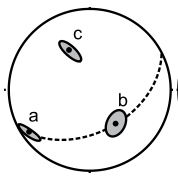

AB-7

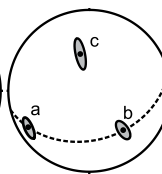

AB-6

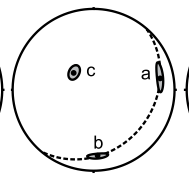

AB-5

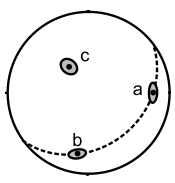

AB-4

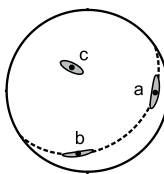

AB-3

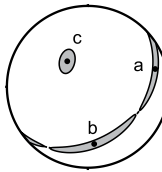

AB-2

C

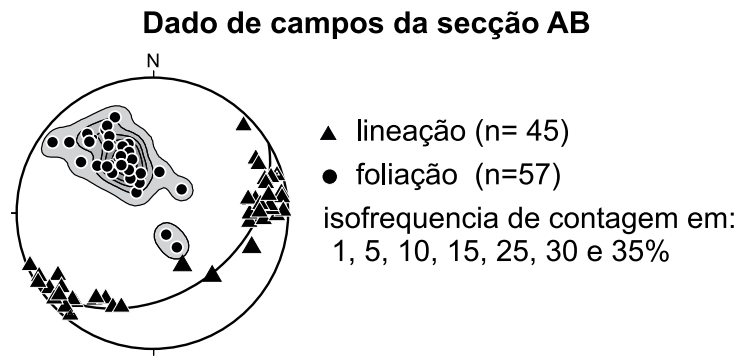

Figura 10. A. Gráficos T (parâmetro de forma) x distâncias e P (grau de anisotropia) x distâncias dos afloramentos analisados na secção estudada ao longo do Rio Mamanguape nas proximidades do município de Alagoa Grande. B. Secção geológica $A B$ com respectivos elipsoides de forma (método dos interceptos a partir de imagens tratadas). C. Dados de campo da secção $A B$. 
SR (razão de forma) ocorrem sempre com valores menores que os obtidos pelo tensor de inércia. Esta característica de valores menores de P e SR no método dos interceptos, comparados com outros métodos de quantificação, já foi identificada no trabalho de Rodrigues e Faleiros (2007) e Rodrigues, Archanjo e Launeau (2009). Este comportamento é associado à característica do método dos interceptos de analisar as imagens considerando uma população de linhas com diferentes orientações, de forma que direções secundárias são levadas em conta no cálculo da razão de forma, podendo influenciar os valores finais. Já no método do tensor de inércia somente é considerado a direção principal de orientação de cada grão. Outro fator importante que altera os resultados dos parâmetros calculados $(\mathrm{P}, \mathrm{T}$ e SR) e das orientações da OPFs são orientações preexistentes na rocha indeformada e as razões iniciais dos objetos/grãos $\left(\mathrm{R}_{\mathrm{i}}\right)$.

Os valores obtidos de parâmetro P (grau de anisotropia) e SR (razão de forma) nos métodos e imagens utilizados variam de 2,0 a 4,0, sendo que apresentam, no geral, valores próximos a 2,0. Estes valores indicam baixas taxas de deformação nas tramas analisadas.

Quanto ao tipo de elipsoides, os afloramentos AB-1, AB-2, AB-3, AB-4 e AB-9 são oblatos (campo da deformação por achatamento, ver Figura 10A), com valores de $\mathrm{T}$ positivos. Os outros afloramentos apresentam elipsoides situados no limite do campo entre oblato e prolato (campo da deformação plana) por possuírem valores de $\mathrm{T}$ próximos de zero. Somente o afloramento AB-6 caracteriza-se como elipsoide do tipo prolato (campo da deformação por estiramento) por possuir valor de T negativo. Desta forma, as tramas minerais caracterizam-se como planares a plano-lineares (tectonitos S, Turner e Weiss, 1963) ao longo do perfil analisado.

\section{DISCUSSÕES E CONCLUSÕES}

Os Metagranitoides Cariris Velhos apresentam características isotópicas e geocronológicas bem definidas relacionadas ao "Evento Cariris Velhos", que define um importante evento de acreção e geração de crosta de idade toniana ( $\sim 950 \mathrm{Ma}$ ) na Zona Transversal. Os elipsoides de deformação obtidos nos Metagranitoides Cariris Velhos, juntamente com os dados de campo, são importantes para compreensão da evolução estrutural da referida área.

As análises dos gráficos $R_{f} / \phi$ das seções analisadas (seções $m n$, mo e no) nos afloramentos estudados apresentam distribuição de $\mathrm{R}_{\mathrm{f}}$ simétricas e com distribuição normal (indicativa de baixas taxas de deformação e $R_{i}>R_{s}$ ). $\mathrm{O}$ comportamento observado indica que não há uma orientação significativa das tramas minerais anteriores a deformação, sendo que os objetos originais (fenocristais de feldspato) eram provavelmente inequidimensionais $\left(\mathrm{R}_{\mathrm{i}}>\right.$ 1). As tramas atuais analisadas de objetos/grãos (porfiroclastos de feldspatos) apresentam formas parcialmente deformadas e orientadas. A não orientação prévia das tramas minerais analisada, também pode ser usada, como um argumento de que não exista uma deformação anterior à caracterizada nas tramas minerais observada nos Metagranitoides Cariris Velhos.

No perfil analisado, os Metagranitoides Cariris Velhos apresentam características bem definidas quanto aos elipsoides de deformação obtidos. Destacam-se a forte orientação do eixo C (associado ao polo da foliação) e o predomínio de elipsoides associados a tramas planares e plano-lineares. Os valores obtidos de parâmetro $\mathrm{P}$ (grau de anisotropia) e SR (razão de forma) nos métodos e imagens utilizados variam de 2,0 a 4,0, sendo que apresentam no geral valores próximos a 2,0. Este valores indicam baixas taxas de deformação nas tramas analisadas. O comportamento apresentado pelos elipsoides reflete a estrutura observada em campo. Esta estrutura caracteriza um domínio de foliações de natureza milonítica de caimento médio de direção NE-SW ( N55E/35 SE), com lineações distribuídas ao longo do eixo NE-SW com variações da obliquidade porém, no geral, com valores baixos.

A estrutura delimitada no perfil do Rio Mamanguape apresenta características estruturais mistas em relação às zonas de cisalhamento regionais. $\mathrm{O}$ comportamento da distribuição da foliação milonítica e do eixo $\mathrm{C}$ dos elipsoides no perfil do Rio Mamanguape é relativamente similar ao observado próximo a Zona de Empurrão de Riachão de Bacamarte (Figura 2), onde predominam foliações de direção NW-SE, com caimentos médios. O comportamento das lineações é no geral similar ao observado nas zonas de cisalhamento transcorrentes (Zona de Cisalhamento Matinhas), onde predominam lineações de baixa obliquidade orientadas no eixo NE-SW, mas que estão associadas a uma foliação de alto ângulo (Figura 2). Algumas das lineações observadas em campo (Figura 10C) e no elipsoide AB-2 (Figura 9) constituem-se em exceções a este padrão com lineações oblíquas (down dip) com orientação SE, que são comumente observadas na Zona de Empurrão de Riachão de Bacamarte (Figura 2). Os indicadores cinemáticos observados no perfil denotam um componente de movimentação lateral obliqua que ressaltam características possivelmente associadas a uma rampa lateral de uma nappe/ou lasca tectônica.

A correlação da estrutura observada ao longo do Rio Mamanguape é relacionada com a evolução de um sistema de cisalhamento caracterizado por falhas transcorrentes e empurrão, caracterizado por Rodrigues e Archanjo (2008) como um sistema transpressivo denominado "Sistema de Cisalhamento de Campina Grande", resultante de esforços 
compressivos de direção NNW-SSE. Esta direção de compressão é compatível com a orientação (principalmente do eixo A: NE-SW) e a forma (achatada) dos elipsoides obtidos no perfil do Rio Mamanguape.

Rodrigues e Archanjo (2008) associam o "Sistema de Cisalhamento de Campina Grande" com modelos de formação de falhas transcorrentes conjugadas associadas a esforços coaxiais (Ramsay e Lisle, 2000; McClay, 1987). Neste caso, a deformação regional seria dominantemente coaxial e afetaria um sistema fortemente anisotrópico constituído por rochas previamente foliadas. Sendo que as zonas de cisalhamentos principais constituiriam domínios onde predominaria a deformação não-coaxial. Os referidos autores apontam como evidências de deformação coaxial, algumas tramas de eixo c de quartzo simétricas e levemente assimétricas (guirlandas cruzadas do tipo I, Schmid e Casey, 1986; Law, 1990 etc.).

O "Sistema de Cisalhamento de Campina Grande" apresenta seu período principal de evolução situado no intervalo de 590 a $570 \mathrm{Ma}$, associado a intenso magmatismo granítico, no qual as zonas de cisalhamento transcorrentes tiveram importante papel no alojamento dos plútons graníticos, conforme os trabalhos de Rodrigues, Archanjo e Launeau (2009) e Rodrigues (2008).

O "Sistema de Cisalhamento de Campina Grande", conforme Rodrigues e Archanjo (2008) representa o produto da interação dos segmentos crustais da Zona Transversal, possivelmente associado a eventos transpressivos. Transpressivo no sentido inicialmente proposto por Harland (1971) que descreve a movimentação convergente oblíqua entre dois blocos crustais, ou a movimentação particionada entre convergência e transcorrência.

A aplicação de um modelo de transpressão proposto na literatura (Sanderson e Marchini, 1984; Tikoff e Teyssier, 1994) é corroborada pela propriedade onde as lineações deveriam ser horizontais quando a transcorrência é dominante (conforme observado nas zonas de cisalhamento transcorrentes - vide Figura 2) e de máximo mergulho na predominância de movimentos verticais (Zona de Empurrão de Riachão de Bacamarte - vide Figura 2). A aplicação de um modelo de transpressão também é compatível com predomínios de tramas minerais planares e plano-lineares observadas ao longo do Rio Mamanguape, que são associadas ao campo do achatamento que predomina em regimes transpressivos. No entanto, ressalta-se que a aplicação de um modelo de transpressão deve ser utilizado com parcimônia, e que outras hipóteses podem ser utilizadas para explicar o comportamento das lineações observadas na área estudada.

A aplicação de um modelo de transpressão, no geral, esbarra nos pressupostos teóricos de que em modelos idealizados (por exemplo, os de Sanderson e Marchini,
1984; Tikoff e Teyssier, 1994) não existem lineações oblíquas. A presença de lineações oblíquas descarta, no geral, a aplicação destes modelos e apresenta-se também como o maior obstáculo a aplicação de outros modelos propostos para a transpressão. Czeck e Hudleston (2003) testam diversos modelos teóricos de transpressão da literatura que apresentam lineações oblíquas e indicam que os mesmos são insuficientes para explicar tais lineações dentro de exemplos naturais, em grande parte, por não explicarem lineações com caimentos em rumo diferentes. Os mesmos apresentam um novo modelo para explicar lineações oblíquas dentro de zona de transpressão com componente de extrusão não vertical e variável, enquanto a direção do sentido do cisalhamento simples é constante e não vertical. As condições físicas necessárias para gerarem estas condições incluem variações na litologia, resistência e variação na orientação nos limites da zona e localização de esforços. No entanto para este modelo as lineações têm que apresentar concentrações máximas de alto ângulo, o que pode ser compatível, em parte, com as lineações observadas no Sistema de Empurrão de Riachão do Bacamarte e em algumas porções do perfil do Rio Mamanguape.

Em parte, as diferenças nas lineações e foliações observadas nas zonas de cisalhamento regionais e ao longo do perfil do Rio Mamanguape podem também ser explicadas por uma resposta heterogênea à deformação (como proposto por Hudleston, 1999) e pela partição da deformação.

\section{AGRADECIMENTOS}

Os autores agradecem à FAPESP (processos $\mathrm{n}^{\circ}$. 02/13677-4 e 02/14687-1) pelo apoio financeiro e aos revisores anônimos pelas importantes contribuições sugeridas ao trabalho.

\section{REFERÊNCIAS}

ALMEIDA, C. N.; GUIMARÃES, I. P.; SILVA FILHO, A. F. Petrogênese de rochas plutônicas félsicas e máficas na província Borborema, NE do Brasil: o complexo Cálcio Alcalino de Alto-K de Campina Grande. Revista Brasileira de Geociências, v. 32, p. 205-216, 2002a.

ALMEIDA, C. N.; GUIMARÃES, I. P.; SILVA FILHO, A. F. A-Type Post-collisional Granites in the Borborema Province - NE Brazil: The Queimadas Pluton. Gondwana Research, v. 5, p. 667-681, 2002 b.

ALMEIDA, F. F. M.; HASUI, Y.; BRITO NEVES, B. B.; FUCK, R. A. Brazilian structural provinces: an introduction. Earth-Science Reviews, v. 17, p. 1-21, 1981. 
ARCHANJO, C. J.; FETTER, A.H. Emplacement setting of the granite sheeted pluton of Esperança (Brasilian Orogen, Northeastern Brazil). Precambrian Research, v. 135, p. 193-215, 2004.

ARCHANJO, C. J.; HOLLANDA, M. H. B. M.; RODRIGUES, S. W. O; BRITO NEVES, B. B.; ARMSTONG, R. Fabrics of pre- and syntectonic granite plutons and chronology of shear zones in the Eastern Borborema Province, NE Brazil. Journal of Structural Geology, v. 30, p. 310-336, 2008.

BRITO NEVES, B. B. Regionalização geotectônica do Pré-cambriano Nordestino. 1975. 198 f. Tese (Doutorado) - Instituto de Geociências, Universidade de São Paulo. São Paulo, 1975.

BRITO NEVES, B. B. O mapa geológico do Nordeste Oriental do Brasil, escala 1:1.000.000. 1983. 177 f. Tese (Livre Docência) - Instituto de Geociências, Universidade de São Paulo, São Paulo, 1983.

BRITO NEVES, B. B.; VAN SCHMUS, W. R.; SANTOS, E. J.; CAMPOS NETO, M. C. O evento Cariris Velhos na Província Borborema: integração de dados, implicações e perspectivas. Revista Brasileira de Geociências, v. 25, p. 151-182, 1995.

BRITO NEVES, B. B.; SANTOS, E. J.; VAN SCHMUS, W. R. Tectonic history of the Borborema Province. In: CORDANI, U. G.; MILANI, E. J.; THOMAZ FILHO, A.; CAMPO, D. A. (Ed.). Tectonic evolution of the South America. Rio de Janeiro, 2000. p. 151-182.

BRITO NEVES, B. B.; CAMPOS NETO, M. C.; VAN SCHMUS, W. R.; SANTOS, E. J. O Sistema Pajeú-Paraíba e o Maciço São José do Campestre no Leste da Borborema. Revista Brasileira de Geociências, v. 31, p. 173-184, 2001 a.

BRITO NEVES, B. B.; CAMPOS NETO, M. C.; VAN SCHMUS, W. R.; FERNANDES, M. G. G.; SOUZA, L. O. O Terreno Alto Moxotó no Leste da Paraíba (Maciço Caldas Brandão). Revista Brasileira de Geociências, v. 31, p. 185-194, 2001b.

BRITO NEVES, B. B.; GUIMARÃES I. P., SANTOS, E. J.; VAN SCHMUS, W. R.; CAMPOS NETO, M. C. Geology, Geochemistry and Geochronology (Rb-Sr, U-Pb, $\mathrm{Sm}-\mathrm{Nd}$ and $\mathrm{Ar}-\mathrm{Ar}$ ) of the orthogneisses from the Alto Pajeú Terrane. . In: SOUTH AMERICAN SYPOSIUM OF ISOTOPE GEOLOGY, 4., 2003, Salvador. Short Papers... Salvador: CBPM/IRD, 2003. p. 155-157.
BRITO NEVES, B. B.; VAN SCHMUS, W. R.; KOZUCH, M.; SANTOS, E. J.; PETRONILHO, L. A Zona Tectônica Teixeira Terra Nova -ZTTTN -Fundamentos da Geologia Regional e Isotópica. Geologia USP: Série Cientifica, São Paulo, v. 5, p. 57-80, 2005.

CZECK, M. D.; HUDLESTON, P. J. Testing models for obliquely plunging lineations in transpression: a natural example and theoretical discussion. Journal of Structural Geology, v. 25: p. 959-982, 2003.

GUIMARÃES, I. P.; BRITO NEVES, B. B. Caracterização geoquímica de parte do plutonismo Eo-Neoproterozóico no limite norte do domínio estrutural central da Província Borborema. In: CONGRESSO BRASILEIRO DE GEOQUÍMICA, 10., 2005, Porto de Galinhas. Anais... Porto de Galinhas: SBGq, 2005. p. 594-597.

HARLAND, W. B. Tectonic transpression in Caledonian Spitsbergen. Geological Magazine, v. 10. p. 27-42, 1971.

HARVEY, P. K.; LAXTON, R. R. The estimation of finite strain from the orientation distribution of passively deformed linear markers: eigenvalue relationships. Tectonophysics, v. 70. p. 285-307, 1980.

HUDLESTON, P. Strain compatibility and shear zones: is there a problem? Journal of Structural Geology, v. 21. p. 923-932, 1999.

$\mathrm{KOZUCH}, \mathrm{M}$. Isotopic and trace element geochemistry of early Neoproterozoic gneissic and metavolcanic rocks in the Cariris Velhos Orogen of Borborema Province, Brazil, and their bearing on tectonic setting. 2003. 199 f. Tese (Doutorado) - University of Kansas, Kansas, 2003.

LAUNEAU, P.; BOUCHEZ, J. L.; KEITH, B. Shape preferred orientation of object population: automatic analysis of digitized images. Tectonophysics, v. 180, p. 201-211, 1990.

LAUNEAU, P.; CRUDEN, A. R. Magmatic fabric acquisition mechanism in a syenite: results of a combined anisotropy of magnetic susceptibility and image analysis study. Journal of Geophysical Research, v. 103, p. 5067-5068, 1998.

LAUNEAU, P.; ROBIN, P. Y. F. Fabrics analysis using the intercept method. Tectonophysics, v. 267, p. 91-119, 1996.

LAUNEAU, P.; ROBIN, P. Y. F. INTERCEPTS v. 2003 (freeware). Université de Nantes (França)/University of 
Toronto (Canadá). 2003a. Disponível em: $<\underline{\text { http://www. }}$ sciences.univ-nantes.fr/geol/UMR6112/SPO/Intercepts. html >. Acesso em: 26 set. 2005.

LAUNEAU, P.; ROBIN, P. Y. F. SPO v. 2003 (freeware). Université de Nantes (França)/University of Toronto (Canadá). 2003b. Disponível em: $<\underline{\text { http://www.sciences. }}$ univ-nantes.fr/geol/UMR6112/SPO/SPO.html>. Acesso em: 13 jan. 2005.

LAUNEAU, P.; ROBIN, P. Y. F. ELLIPSOID v. 2003 (freeware). Université de Nantes (França)/ University of Toronto (Canadá). 2003c. Disponível em: $<$ http://www. sciences.univ-nantes.fr/geol/UMR6112/SPO/Ellipsoid. html >. Acesso em: 13 jan. 2005.

LISLE, R. J. Geological strain analysis: a manual for the Rf/phi technique. Oxford: Pergamon Press, 1985. 60 p.

LAW, R. D. Crystallographic fabrics: a selective review of their applications to research in structural geology. In: KIPE, R. J. ; RUTTER, E. H. (Ed.). Deformations Mechanism, Rheology and tectonics. London: Geological Society, 1990. p. 335-352. (Special Publication, v. 54).

MARIANO, G.; NEVES, S. P.; SILVA FILHO, A. F.; GUIMARÃES, I. P. Diorites of the high-K calcalkalic association: geochemistry and $\mathrm{Sm}-\mathrm{Nd}$ data and implications for the evolution of the Borborema province, northeast Brazil. International Geology Review, v. 43, p. 921-929. 2001.

McCLAY, K. The mapping of geological structures. New York: John Wiley, 1987. 162 p.

NEVES, S. P. Proterozoic history of the Borborema province (NE Brazil): correlation with neighboring cratons and Pan-African belts and implications for the evolution of western Gondwana. Tectonics, v. 22, p. 1031. 2003.

NEVES, S. P.; MARIANO, G.; GUIMARÃES, I. P.; SILVA FILHO, A. F.; MELO, S. C. Intralithospheric differentiation and crustal growth: evidence from the Borborema Province, Northeastern Brazil. Geology, v. 28, p. 519-522, 2000.

PEACH, C. J.; LISLE, R. J. A Fortran IV program for the analysis of tectonic strain using deformed elliptical markers. Computer \& Geosciences, v. 5, p. 325-334, 1979.

RAMSAY, J. G. Folds and fracturing of rocks. New York: McGraw Hill, 1967. 568 p.
RAMSAY, J. G.; HUBER, M. I. The Techniques of modern structural geology. Volume I: strain analysis. London: Academic Press, 1983. 307 p.

RAMSAY, J. G.; HUBER, M. I. The Techniques of Modern Structural Geology. Volume II: Folds and Fractures. London: Academic Press, 1987. 391 p.

RAMSAY, J. G.; LISLE, R. J. The Techniques of Modern Structural Geology, Volume 3: Applications of Continuum Mechanics in Structural Geology. London: Academic Press, 2000. 560 p.

ROBIN, P. Y. F. Determination of fabric and strain ellipsoids from measured sectional ellipses - Theory. Journal of Structural Geology, v. 24, p. 531-544, 2002.

RODRIGUES, S. W. O. Evolução estrutural e geocronológica da Província Borborema na região de Campina Grande (PB). 2008. 178 f. Tese (Doutorado) Instituto de Geociências, Universidade de São Paulo, São Paulo, 2008.

RODRIGUES, S. W. O.; FALEIROS, F. M. Avaliação de métodos de quantificação da deformação finita por meio de simulações computacionais de deformação progressiva. Revista Brasileira de Geociências, v. 37, p. 504-514, 2007.

RODRIGUES, S.W.O.; ARCHANJO, C. J. Microestruturas e tramas de eixo $\mathrm{C}$ de quartzo em milonitos do Sistema de Cisalhamento Campina Grande (PB), Província Borborema. Revista Brasileira de Geociências, v. 38, p. 392-405, 2008.

RODRIGUES, S. W. O.; BRITO NEVES, B. B. Padrões isotópicos SM-Nd no limite entre os Terrenos Alto Pajeú e Alto Moxotó (PB). Revista Brasileira de Geociências, v. 38, p. 209-225, 2008.

RODRIGUES, S. W. O.; ARCHANJO, C. J.; LAUNEAU, P. Determinação da orientação preferencial de forma (OPF) de silicatos em rochas graníticas: granito Campina Grande (PB). Revista Brasileira de Geociências, v. 39, p. 435-451, 2009.

SÁ, E. F. J. A Faixa Seridó (Província Borborema, NE do Brasil) e o seu significado geodinâmico na cadeia Brasiliana/ Pan-Africana. 1994. 804 f. Tese (Doutorado) - Instituto de Geociências, Universidade de Brasília, Brasília, 1994.

SAMPAIO, M. A.; GUIMARÃES I. P.; ALMEIDA C.N.; CARMONA, L .C. M. Rb-Sr and Sm-Nd isotope 
geochemistry of granitoids from the Esperança granitic complex, Paraíba state, Borborema Province, Northeast Brazil. In: SOUTH AMERICAN SYPOSIUM OF ISOTOPE GEOLOGY. 4., 2003, Salvador. Short Papers... Salvador: CBPM/IRD, 2003. p. 122-123.

SANDERSON, D. J; MARCHINI, W. R. D. Transpression. Journal of Structural Geology, v. 6, p. 449-458, 1984.

SANTOS, E. J. Complexo Granítico Lagoa das Pedras: acresção e colisão na região de Floresta (Pernambuco), Província Borborema. 1995. 220 f. Tese (Doutorado) Instituto de Geociências, Universidade de São Paulo, São Paulo, 1995.

SANTOS, E. J.; BRITO NEVES, B. B. Província Borborema. In: ALMEIDA, F. F. M.; HASUI, Y. (Coord.). O Pré-Cambriano do Brasil. São Paulo: Edgar Blucher, 1984. p. 123-186.

SANTOS, E. J.; VAN SCHMUS, W. R.; BRITO NEVES, B. B.; OLIVEIRA, R. G.; MEDEIROS, V. C. Terranes and their boundaries in the Proterozoic Borborema Province, Northeast Brazil. In: SIMPÓSIO NACIONAL DE ESTUDOS TECTÔNICOS, 7., 1999. Anais... Lençóis: SBG-BA, 1999. p. 121-124.

SANTOS E. J.; FERREIRA, C. A.; SILVA JÚNIOR, J. M. F. Geologia e recursos minerais do Estado da Paraíba: texto explicativo do mapa geológico e de recursos minerais. Recife, CPRM, 2002. 2 mapas, col. Escala 1:500.000. 1 CD-ROM.

SANTOS, E. J.; NUTMAN, A. P.; BRITO NEVES, B. B. Idades SHRIMP U-Pb do Complexo Sertânia: implicações sobre a evolução tectônica da Zona Transversal, Província Borborema. Geologia USP: Série Cientifica, São Paulo, v. 4, p. 1-12, 2004.

SANTOS, E. J., VAN SCHMUS, W. R., KOZUCH, M., BRITO NEVES, B. B.. The Cariris Velhos Tectonic Event in Northeast Brazil. Journal of South American Earth Sciences, v. 29, n. 1, p. 61-76, 2010.

SCHIMID, S.; CASEY, M.. Complete fabric analysis of some commonly observed quarzt c-axis patterns. In: Hobbs, B. E.; Heard, H. C. (Ed.). Mineral and Rock Deformation: laboratory studies. Washington: American Geophysical Union, 1986. p. 263-286. (Geophysical Monography, 36).

SHIMAMOTO, I.; IKEDA, Y. A simple algebraic method for strain estimation from deformed ellipsoidal methods. Tectonophysics, v. 36, p. 315-317, 1976.
TIKOFF, B.; TEYSSIER, C. Strain modeling of displacement-field partioning in transpressional orogens. Journal of Structural Geology, v. 16, p. 1575-1588, 1994.

TURNER, F. J.; WEISS, L. E. Structural analysis of Metamorphic tectonites. New York: McGraw-Hill, 1963, $560 \mathrm{p}$.

VAN SCHMUS, W. R.; BRITO NEVES, B. B.; HACKSPACHER, P. C.; BABINSKI, M. U-Pb and Sm$\mathrm{Nd}$ geochronological studies of the eastern Borborema Province, Northeastern Brazil: initial conclusions. Journal of South American Earth Science, v. 8, p. 267-288, 1995. 